\title{
Jurisprudencia reciente de la Corte Suprema de Chile sobre infracción a normas reguladoras de la prueba en el ámbito tributario
}

\author{
Manuel Rodríguez Vega* \\ Patricio Casas Farias**
}

\begin{abstract}
RESUMEN
El presente trabajo examina las sentencias dictadas durante el 2016 por la Corte Suprema de Chile al resolver recursos de casación en el fondo en materias tributarias en que se acusa por alguna de las partes la infracción de normas reguladoras de la prueba, en particular las reglas de valoración de la sana crítica. Ello, con el objeto de evidenciar la forma en que nuestro máximo Tribunal ha conceptualizado dichas reglas de ponderación, distinguiendo esa infracción sustantiva de los meros defectos de fundamentación y rechazando por esa vía abocarse a un nuevo establecimiento de hechos, cuestión que, como se demostrará, no ha sido asimilada aún por los litigantes de la especialidad, conllevando que los recursos presentados en relación con el punto en comento no hayan prosperado. Asimismo, se confronta esta tendencia jurisprudencial con la posición de la doctrina acerca de la materia, particularmente respecto de la motivación insuficiente de las sentencias como causal de casación en el fondo por infracción a normas reguladoras de la prueba.
\end{abstract}

Jurisprudencia - Corte Suprema de Chile - valoración prueba - sana crítica derecho tributario

\section{Recent jurisprudence of the Chilean Supreme Court on violation of regulatory standard of proof in tax matters}

\begin{abstract}
SUMMARY
This paper examines the jurisprudence issued during the year 2016 of the Supreme Court of Chile produced by resolving appeals in cases in which one of the parties accuse violating norms of evidence, in particular, the rules of "sane criticism" (sana critica). This, in order to highlight the way in which our High Court has conceptualized such rules of valuation, distinguishing
\end{abstract}

* Licenciado en Ciencias Jurídicas y Sociales, Pontificia Universidad Católica de Chile. Magíster en Derecho, Universidad de Talca. Doctor en Derecho, Universidad de Chile. Profesor de Derecho Tributario, Facultad de Ciencias Jurídicas y Sociales y de la Facultad de Economía y Negocios de la Universidad de Talca. Correo electrónico: manrodriguez@utalca.cl

** Licenciado en Ciencias Jurídicas y Sociales, Universidad de Chile. Ayudante ad honorem del Departamento de Derecho Procesal y de la Clínica Tributaria, Universidad de Chile. Correo electrónico: pcasasf@ug.uchile.cl.

Artículo recibido el 29 de enero de 2017 y aceptado para su publicación en este número el 23 de enero de 2018. 
this substantive infringement from the mere defects of justification and rejecting by that way to refer to a new assessment of the facts, a question that, We will prove, has not yet been assimilated by the litigants of the specialty, implying that the appeals presented in relation to the point in question have not prospered. Likewise, this jurisprudential tendency is confronted with the position of the doctrine on the subject, particularly regarding the insufficient reasoning of the judgments as grounds for cassation in the fund for violation of norms that regulate the evidence

Jurisprudence - chilean Supreme Court - valuation test - sane criticism - tax law

\section{INTRODUCCIÓN}

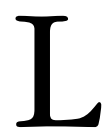

a dictación de la Ley N 20.322 que "Fortalece y Perfecciona la Justicia Tributaria y Aduanera", cuya gradual entrada en vigencia concluyó con el inicio de las funciones 1 de los cuatro Tribunales Tributarios y Aduaneros de la Región Metropolitana en el 2013, supuso la modernización de un sistema de jurisdicción tributaria constantemente cuestionado. Estos cuestionamientos, provenientes de diversos sectores ${ }^{1}$, impulsaron esta reforma al sistema jurisdiccional tributario chileno, dando lugar a profundas modificaciones a los procedimientos, otorgando la calidad procesal de parte al Servicio de Impuestos Internos (en adelante también SII o "Servicio") y creó los Tribunales Tributarios y Aduaneros, los que fueron considerados como tribunales especiales de aquellos del inciso $4^{\circ}$ del artículo 5 del Código Orgánico de Tribunales, desatendiendo la sugerencia de la Corte Suprema de incluirlos como parte del Poder Judicial ${ }^{2}$.

A su vez, se modificó el Código Orgánico de Tribunales en su artículo 66, estableciendo que ciertas Cortes de Apelaciones designarían una sala exclusivamente dedicada al conocimiento de asuntos tributarios y aduaneros, realizándose dicha designación por medio de un auto acordado que se debería dictar cada dos años ${ }^{3}$. Por su parte, se designó la Segunda Sala Penal de la Corte Suprema para el conocimiento de estas causas ${ }^{4}$,

\footnotetext{
${ }^{1}$ La crítica puede encontrarse en el desarrollo mismo de la tramitación del Proyecto de Ley que Fortalece y Perfecciona la Jurisdicción Tributaria y en el Mensaje contenido al momento de su ingreso según el Boletín $\mathrm{N}^{\circ}$ 206-348 de 19 de noviembre de 2002 y que concluyó finalmente en la Ley $\mathrm{N}^{\circ} 20.322$ que creó los Tribunales Tributarios y Aduaneros. Al respecto también es posible ver: Greiber Pablo, Ocampo, Luis Felipe, Seguel Luis. "Justicia Tributaria y Delegación de Facultades Jurisdiccionales: Análisis de la Jurisprudencia reciente del Tribunal Constitucional”. En Anuario de Doctrina y Jurisprudencia, Sentencias Destacadas, año 2006, Instituto Libertad y Desarrollo. Santiago, abril de 2007.

${ }^{2} \mathrm{Al}$ respecto es posible revisar los Oficios $\mathrm{N}^{\mathrm{o}} 3643-2002$ de 30 de diciembre de 2002 y No $178-2005$ de 6 de diciembre de 2005 de la Corte Suprema en el marco de la tramitación de la Ley $\mathrm{N}^{\circ} 20.322$. Uno de los efectos prácticos centrales de no integrar a estos magistrados al Poder Judicial, según se verá, dice relación con la imposibilidad de ascenso en la escala de ese Poder, evitando de ese modo que puedan conformar las salas especializadas de las Cortes de Apelaciones o integrar la sala tributaria de la Corte Suprema, salvo respecto de los cupos que se completan con abogados externos al Poder Judicial.

${ }^{3}$ Por ejemplo, en el caso de la Corte de Apelaciones de Santiago, el último auto acordado en entrar en vigencia S/N fue emitido el 13 de marzo de 2015, estableciendo también la forma en la que se capacitarán los ministros en materias tributarias y aduaneras para el conocimiento de estas causas.

${ }^{4}$ Acta 233-2014, auto acordado de la Corte Suprema S/N publicado el 16 de enero de 2015.
} 
la que se encarga en la actualidad principalmente de los recursos de casación en la forma y en el fondo interpuestos en los procesos de reclamo tributario. Este perfeccionamiento de la jurisdicción tributaria no solo acarreó una modificación orgánica de los Tribunales llamados a conocer de estas causas, sino también dio lugar a la creación de nuevos procedimientos y a la modificación sustancial del que concentra la mayor cantidad de causas vigentes, esto es, el procedimiento general de reclamo.

Una de las modificaciones centrales a ese procedimiento atinge al sistema de valoración de la prueba, transitando desde uno gobernado por la prueba legal tasada a uno regido por la "sana crítica", con una regla de admisibilidad laxa que acepta cualquier medio apto para producir fe $\mathrm{f}^{5}$ La norma que regula esta cuestión es el inciso $14^{\mathrm{o}} \mathrm{del}$ artículo 132 del actual Código Tributario ${ }^{7}$, que dispone: La prueba será apreciada por el Juez Tributario y Aduanero de conformidad con las reglas de la sana crítica. Al apreciar las pruebas de esta manera, el tribunal deberá expresar en la sentencia las razones jurídicas y las simplemente lógicas, científicas, técnicas o de experiencia en virtud de las cuales les asigna valor o las desestima. En general, tomará en especial consideración la multiplicidad, gravedad, precisión,

${ }^{5}$ El Máximo Tribunal ha dado cuenta de este cambio en diversos pronunciamientos, como en la causa Rol No 11.183-15 de 30 de junio de 2016 se explica que los artículos 1700, 1702 y 1707 del Código Civil y 346 del Código de Procedimiento Civil, que tratan el valor probatorio de las declaraciones efectuadas en instrumentos públicos y privados, no tienen aplicación en este procedimiento en que la prueba se aprecia conforme a las reglas de la sana crítica (cons. $5^{\circ}$ ). Del mismo modo, en la causa Rol No 26.854-14 de 15 de septiembre de 2016 se resuelve que en el arbitrio de casación se invoca una norma que no tiene aplicación en este procedimiento $-346 N^{\circ} 1$ del Código de Procedimiento Civil-, pues si el documento se considera o no reconocido por quien aparece haberlo otorgado es algo que debe determinar el juez de la instancia conforme a las reglas de la sana crítica y no según dicha disposición (c. $16^{\circ}$ ). En la causa Rol No 26.914-15 de 22 de septiembre de 2016 se manifestó que en lo referido a los artículos 1702 del Código Civil, $346 N^{\circ} 3$ y 348 del Código de Procedimiento Civil, dichos preceptos no rigen la valoración de la prueba en este procedimiento general de reclamación, asunto que se gobierna por las reglas de la sana crítica, como dispone el artículo 132, inciso $1^{\circ}$, del Código Tributario (cons. $7^{\circ}$ ). Y en el proceso Rol No 26.911-2015 de 11 de octubre de 2016 se expresa que Al haber sido tramitado el reclamo de acuerdo con el procedimiento tributario establecido por la Ley $N^{\circ} 20.322$, esa cuestión de hecho debía ser zanjada mediante la valoración de las pruebas conforme con las reglas de la sana crítica, de acuerdo con lo prevenido por el artículo 132 inciso $14^{\circ}$ del Código Tributario, pauta que implica una libre apreciación del juez, fundada racionalmente dentro de los márgenes de la lógica, las máximas de la experiencia y los conocimientos científicamente afianzados, de manera que cada uno de los medios de convicción no se sujeta a un análisis individual sino que, muy por el contrario, se incorpora dentro del conjunto de la evidencia rendida que, ponderada en su totalidad, sirve de base a las conclusiones fácticas. Por tal motivo, resulta claro que los artículos 342 del Código de Procedimiento Civil, 1700 y 1702 del Código Civil y 419 del Código Orgánico de Tribunales, no son normas aplicables a esta litis en materia probatoria, por lo que no es procedente su análisis (cons. $4^{\circ}$ ).

${ }^{6}$ A partir de la reforma de la Ley $N^{\circ} 21.039$ del 20 de octubre de 2017 , el inciso $14^{\circ}$ pasó a ser el $15^{\circ}$. Lo anterior, a partir de la inclusión del inciso segundo en dicho artículo, que introduce el trámite obligatorio de la conciliación tributaria consagrada en el artículo 132 bis del Código Tributario. Para efectos de este trabajo, y atendida consideración a la fecha que abarca la muestra de jurisprudencia analizada, se hace referencia al inciso $14^{\circ}$ por ser específicamente la norma que contenía la valoración de la prueba en materia tributaria a dicha fecha.

${ }^{7}$ Cuestión resistida por algunos sectores durante la discusión en el Congreso del proyecto de ley, principalmente por el desconocimiento del sistema de valoración racional de la prueba y la desconfianza que generaba la posibilidad que dicha norma condujera a un sistema de íntima convicción. Al respecto, por ejemplo, se puede revisar la opinión del Colegio de Abogados A.G. en la Historia de la Ley N N $^{\circ} 2.322$, p. 46 y 146 y la discusión de la Comisión de hacienda, p. 22. 
concordancia y conexión de las pruebas o antecedentes del proceso que utilice, de manera que el examen conduzca lógicamente a la conclusión que convence al sentenciador.

A diferencia de lo que sucede en materia procesal penal y procesal laboral, la elección adoptada por el legislador para la redacción del artículo 132 inciso $15^{\circ}$ del Código Tributario permite expresar con claridad cuál ha de ser el contenido de la fundamentación de la sentencia, al enunciar que para realizar dicha forma de valoración requiere expresar "las razones jurídicas y las simplemente lógicas, científicas, técnicas o de experiencia en

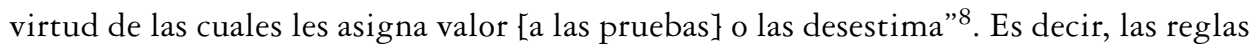
de la lógica, ciencia o experiencia no son representadas como un límite a la motivación de la sentencia del Juez Tributario y Aduanero, sino que constituyen la motivación de la sentencia en sí misma?.

La aplicación de esta norma y la evolución respecto de la comprensión del concepto de sana crítica han generado ciertos criterios a nivel jurisprudencial, particularmente expresados a raíz de los recursos de casación en el fondo deducidos por los contribuyentes en contra de las sentencias de segunda instancia dictadas por las Cortes de Apelaciones. Estos criterios han sido desarrollados por la Corte Suprema al distinguir entre la existencia de una verdadera infracción a una norma acerca de la valoración de la prueba y la mera discrepancia del recurrente con la adjudicación del valor probatorio realizado por la sentencia de alzada, no siendo esto último un vicio que acarree casación. Esto, sin perjuicio de algunos defectos en el control de la fundamentación de la sentencia que se mencionan más adelante.

El que las reglas de la sana crítica, por su naturaleza, no estén fijadas en la ley, sino que han sido conceptualizadas por la doctrina y recogidas por la jurisprudencia, puede dar cuenta del motivo por el que equivocada y habitualmente se planteen errores en la aplicación de las reglas de la sana crítica como defectos de fundamentación, yerro que viene de la mano de dos circunstancias que contribuyen a esto, primero, la exclusión como causal de casación formal por el artículo 768, inciso $2^{\circ}$, del Código de Procedimiento

${ }^{8} \mathrm{Al}$ respecto, por ejemplo el inciso primero del artículo 297 del Código Procesal Penal indica respecto de la valoración de la prueba: "Los tribunales apreciarán la prueba con libertad, pero no podrán contradecir los principios de la lógica, las máximas de la experiencia y los conocimientos científicamente afianzados”. En materia laboral, si bien el artículo 456 del Código del Trabajo adopta en su inciso un segundo, una redacción similar al del actual artículo 132 inciso $15^{\circ}$ del Código Tributario, este último cuerpo normativo no asegura la protección de las reglas de la sana crítica como sí lo hace el Código del Trabajo en el artículo 478 literal b) en relación con las causales del recurso de nulidad. Si bien este recurso procesal no se encuentra consagrado para las causas tributarias, como se indica en el presente trabajo, tampoco ha sido tutelado por el recurso de casación en el fondo.

${ }^{9}$ Lo anterior queda de manifiesto al comparar la redacción del artículo 298 del Código Procesal Penal con la norma acerca de valoración de la prueba en materia tributaria. La expresión de las reglas de la lógica, máximas de la experiencia o conocimientos científicamente afianzados sobre la base en los que se debe motivar la sentencia, ha dado lugar la reiteración de cláusulas de estilo en las sentencias de los Tribunales Tributarios y Aduaneros, por la vía de expresiones como "conforme a las reglas de la sana crítica" o "teniendo en consideración la multiplicidad, gravedad, precisión, concordancia y conexión de las pruebas x,y,z", lo que no es una valoración de la prueba que cumpla con el estándar exigido por la norma, sino que solo es la transcripción del precepto legal. 
Civil en relación con el inciso $2^{\circ}$ del artículo 766 del mismo texto, de la omisión de la sentencia del requisito previsto en el artículo $170 \mathrm{~N}^{\circ} 4$, a saber, Las consideraciones de becho o de derecho que sirven de fundamento a la sentencia ${ }^{10}$; y, segundo, como ya se indicó, el que en el mismo inciso $14^{\circ}$ del artículo 132 del Código Tributario, inmediatamente después de establecerse que la prueba será apreciada por el Juez Tributario y Aduanero de conformidad con las reglas de la sana crítica, se disponga que Al apreciar las pruebas de esta manera, el tribunal deberá expresar en la sentencia las razones jurídicas y las simplemente lógicas, científicas, técnicas o de experiencia en virtud de las cuales les asigna valor o las desestima. En general, tomará en especial consideración la multiplicidad, gravedad, precisión, concordancia y conexión de las pruebas o antecedentes del proceso que utilice, de manera que el examen conduzca lógicamente a la conclusión que convence al sentenciador. En esta segunda parte del párrafo, el legislador establece la forma en que el sentenciador debe exponer el proceso de valoración de la prueba realizado, pero no fija nuevas reglas de valoración cuya conculcación se pueda buscar enmendar vía casación sustantiva y, por consiguiente, la vulneración de dicha disposición constituiría, en opinión de la jurisprudencia, un defecto de carácter ordenatoria litis que, como ya se ha dicho, el legislador ha excluido de ser remediado mediante el recurso de casación en la forma al no existir tal causal para el procedimiento tributario.

Tal modo de plantear los arbitrios de casación en el ámbito de este estudio, como se demostrará, ha sido constantemente desestimado por la Corte Suprema, la que si bien admite la procedencia del recurso por infracción de las reglas de la sana crítica, demanda una precisa indicación de la regla conculcada, como de la influencia sustancial de la misma en lo dispositivo del fallo, exigencias que han significado que los recursos presentados no hayan resultado exitosos en su denuncia, algunos de ellos incluso siendo rechazados en cuenta por la causal de manifiesta falta de fundamento u otros declarados inadmisibles ${ }^{11}$.

${ }^{10}$ El Tribunal Constitucional en diversos fallos ha declarado la inaplicabilidad del inciso $2^{\circ}$ del artículo 768 del Código de Procedimiento Civil, de modo de permitir que dicha causal pueda ser invocada como fundamento de un recurso de casación en la forma deducido en el marco de un procedimiento de reclamación en materia tributaria, por ejemplo, en las causas Rol No 1873-10 de 25 de agosto de 2011, Rol N $2529-13$ de 2 de enero de 2015, Rol No 2677-14 de 4 de junio de 2015, Rol No 2873-15 de 21 de julio de 2016 y Rol No 2898-15 de 21 de julio de 2016.

${ }^{11}$ En la causa Rol No $13.693-15$ de 23 de diciembre de 2015 se rechaza el recurso por manifiesta falta de fundamento de conformidad con el artículo 782 del Código de Procedimiento Civil, ya que ante alegación de la impugnante de que los jueces infringieron el artículo 132, inciso $14^{\circ}$, del Código Tributario por no analizar las operaciones cuestionadas, se expresó que el arbitrio necesita, y en suma pretende, para obtener la invalidación del fallo de segunda instancia, que se alteren los hechos de la causa; sin embargo, una modificación como esa requiere la denuncia de haber incurrido los jueces del fondo en una violación de las leyes reguladoras de la prueba, trasgresión que no ha sido anunciada en el libelo (cons. $4^{\circ}$ ). En términos similares, en las causas Rol $\mathrm{N}^{\circ}$ 7507-16 de 20 de abril de 2016, Rol No 52.947-16 de 6 de septiembre de 2016, Rol No 55.155-16 de 6 de septiembre de 2016 y Rol N $76.347-16$ de 26 de octubre de 2016. En la causa Rol No 31.299-15 de 28 de enero de 2016, al rechazar el arbitrio se declaró que el sistema de valoración de la prueba de la sana crítica, da al sentenciador libertad para ponderar las probanzas del juicio mientras en tal operación no vulnere alguna de las reglas que integran dicho sistema. De ese modo, la parte que sostenga la transgresión de éste, y para aspirar a tener éxito en ello, deberá precisar qué regla específica ha sido conculcada, pues de no existir tal contradicción impera 
En este contexto y como una cuestión previa, se debe indicar que la regulación de la prueba en materia tributaria, desde la incorporación de los Tribunales Tributarios y Aduaneros, ha suscitado varias controversias entre la posición jurisprudencial, la del Servicio de Impuestos Internos y los contribuyentes. Esto, debido a que con la entrada en vigencia del procedimiento general de reclamaciones se produjo la creación de un verdadero procedimiento contencioso administrativo ${ }^{12}$, en cuya aplicación se discutió inicialmente acerca de las facultades del juez para la revisión de los antecedentes aportados por el contribuyente, dando lugar a la tesis del Servicio acerca de la imposibilidad del juez para realizar una nueva auditoría a los antecedentes contables del contribuyente.

El argumento central sostenido por el Fisco es que dicha facultad había sido otorgada por voluntad del legislador al ente fiscalizador, no pudiendo exceder el juez sus facultades

la libertad de apreciación de las probanzas. En otras palabras, no basta reclamar de la inexistencia de una regla de la lógica que apoye las conclusiones fácticas de los jueces, tal como lo hizo el compareciente, pues tal raciocinio desconoce e invierte la operatividad del sistema de la sana crítica que gobierna la materia de autos, demandándose lo que es propio de una valoración tasada o reglada. Por los evidentes defectos en su formalización, no queda sino rechazar el recurso en cuenta, por manifiesta falta de fundamento (cons. $4^{\circ}$ ). En la causa Rol $\mathrm{N}^{\circ}$ 27.707-16 de 13 de junio de 2016 se desestima el arbitrio indicando que del tenor del libelo que contiene la casación en estudio se constata que el recurrente no cuestiona propiamente la aplicación del derecho atinente a la materia, desde que los fundamentos esenciales del recurso dicen relación con el alcance y sentido que corresponde conferir a la prueba rendida en autos. Sin embargo, tal actividad se agotó con la determinación que a ese respecto hicieron los jueces del fondo, quienes tras analizar los antecedentes y en uso de sus facultades privativas, concluyeron que el contribuyente no proporcionó durante el proceso antecedentes suficientes para desmentir lo expuesto por el Servicio de Impuestos Internos, ni logró demostrar la procedencia de la devolución pedida. Y en la medida que la recurrente sugiere algo distinto de lo asentado por los sentenciadores, contraría cuestiones inamovibles en el fallo que impugna. En línea con este último fallo, v. Rol No 5379-16 de 28 de marzo de 2016, Rol No 28.570-16 de 13 de junio de 2016, Rol N ${ }^{\circ}$ 65.263-16 de 21 de septiembre de 2016 y Rol No 65.271-16 de 21 de septiembre de 2016.

En otras oportunidades la Corte ha declarado derechamente la inadmisibilidad del recurso por no cumplir los extremos del artículo 772 del Código de Procedimiento Civil, por ejemplo, en la causa Rol $\mathrm{N}^{\circ}$ 17.075-16 de 20 de abril de 2016 se señala que el arbitrio es inadmisible por cuanto omite señalar los errores de derecho en que incurre el fallo impugnado; razón por la cual no puede acogerse a tramitación. En efecto, el recurrente se limita a citar las normas que considera vulneradas, para luego refutar los fundamentos que llevaron al juez de primera instancia a establecer los bechos que dieron lugar a la decisión que se ataca, careciendo su impugnación del desarrollo exigido por la ley en cuanto al modo cómo se habrían producido las infracciones a las disposiciones que señala y la forma en que ello influiría en lo dispositivo del fallo, lo que es imprescindible atendida la naturaleza de derecho estricto de este extraordinario arbitrio de nulidad sustancial (cons. $5^{\circ}$ ). Se decreta la inadmisibilidad por iguales razones en las causas Rol No 17.727-16 de 20 de abril de 2016, Rol No 23.719-16 de 4 de mayo de 2016, Rol No 24.309-16 de 4 de mayo de 2016, Rol No 31.161-16 de 13 de junio de 2016, Rol No 34.828-16 de 22 de junio de 2016, Rol N 52.879-16 de 25 de agosto de 2016, Rol N58.868-16 de 6 de septiembre de 2016 y Rol No 84.782-16 de 17 de noviembre de 2016.

${ }^{12}$ En una primera etapa se debatió acerca de la naturaleza de este procedimiento, para definir si se trataba de un procedimiento contencioso administrativo equivalente a una acción de nulidad cuyo propósito era que el Juez Tributario y Aduanero realizara un mero control de legalidad formal del acto o bien si se trataba de un procedimiento de plena jurisdicción en cuyo caso la prueba aportada en el proceso sería considerada como uno más de los elementos a tomar en consideración por el juez para la acreditación de los hechos discutidos en el proceso. Al respecto es posible ver: Vergara, Gonzalo. "El reclamo tributario: Características esenciales de un recurso contencioso-administrativo de plena jurisdicción”. En Revista $N^{\circ} 10$ del Centro de Estudios Tributarios de la Universidad de Chile, 2014. pp. 178-208. Luego, argumentando la tesis contraria: BenAvides, Álvaro. Procedencia de una nueva auditoría en el procedimiento general de reclamaciones. Tesis de grado para optar al grado de Magíster en Tributación, Facultad de Economía y Negocios, Universidad de Chile, 2014. 
bajo el argumento de la revisión de la prueba ${ }^{13}$. Sin embargo, tras la superación de esta distinción conceptual luego de un par de años y de criterios disímiles, la jurisprudencia ha podido concentrarse en nuevos aspectos del proceso y de la prueba, entre estos se encuentra la discusión de qué es lo que se debe entender por normas de la sana crítica y cuáles son los alcances de su aplicación en materia tributaria, particularmente en lo referido a la infracción a las normas reguladoras de la prueba y los deberes de fundamentación de las sentencias de los tribunales.

Es en el estudio de dicha jurisprudencia, al menos la más reciente dictada durante el 2016, en el que se centra este trabajo, con el fin de evidenciar cómo han sido conceptualizadas las reglas de la sana crítica por la Corte Suprema y las exigencias que, en coherencia a dicha conceptualización, ha realizado nuestro máximo Tribunal para la procedencia del recurso de casación en el fondo por una eventual infracción a las mismas.

Adicionalmente, se revisa la doctrina que aborda los defectos de fundamentación como causal de casación en el fondo por infracción a las normas reguladoras de la prueba, con el fin de evidenciar el apartamiento de la jurisprudencia de nuestro Tribunal de Casación del tratamiento que los autores han dado a esta materia.

\section{Conceptudulización E IDENTificación DE LAS REglas DE LA SANA CRÍTICA}

Si bien no se ha alcanzado un consenso que permita definir qué es en sentido estricto la sana crítica, sí existe más o menos acuerdo en que dentro de un sistema de valoración de la prueba conforme a esas reglas coexisten las siguientes características: (i) Se hacen depender las conclusiones a las que puede llegar de la aplicación de saberes científicos, de principios de la lógica y de máximas de la experiencia; (ii) Se hacen depender las conclusiones de ciertas formas de construir inferencias que son calificadas como racionales y que el legislador no explicita; (iii) Se opera siguiendo reglas epistémicas que

${ }^{13}$ En la actualidad, en diversos pronunciamientos los Tribunales Tributarios han entendido que el procedimiento de reclamación tributaria es más bien uno de plena jurisdicción en el que tanto el contribuyente como el SII en su calidad de partes pueden aportar prueba para esclarecer los hechos controvertidos del proceso. Dicha prueba será valorada por el juez conforme disponen las normas de la sana crítica, lo que permitirá fundamentar la decisión contenida en la sentencia respectiva, cuestión que va en directa relación con el respeto del derecho a defensa y a la fundamentación de la sentencia como parte del derecho a un debido proceso. Por ejemplo es posible ver dicha posición por la Corte Suprema en Roles No 1160-2013 y No 28748-2014. En la primera de ellas (Cons. $7^{\circ}$ ): Que sin perjuicio de lo razonado, es conveniente asentar que la sede jurisdiccional dista de ser una "segunda revisión" de los antecedentes presentados a la administración, comprensión que se ve ratificada al analizar las disposiciones de excepción que coartan las posibilidades probatorias de las partes, sujetas previamente a la acreditación de precisos y determinados supuestos por parte de la administración, como la contenida en el inciso $11^{\circ}$ del artículo 132 del Código Tributario, lo que en la especie no acontece. Así entonces, los tribunales del grado han de emitir su dictamen sobre todos y cada uno de los asuntos propuestos por las partes, de acuerdo a las normas aplicables al caso, estableciendo los hechos de la causa sobre la base de la prueba rendida y aplicando el derecho pertinente, de manera que la restricción funcional que propone el recurso no se condice con la función asignada por la Constitución y las leyes a los tribunales de justicia (...). Énfasis agregado. 
hacen posible descubrir la verdad a partir de la prueba disponible en el juicio; (iv) se exige explicitación de las razones que han llevado al juzgador a dar por probados los hechos relevantes en el proceso judicial; y (v) Se otorga libertad a los jueces para valorar la prueba disponible. Ello, sin perjuicio que según indica Coloma, hay tensiones entre algunos de los enunciados precedentes, siendo posiblemente el más vistoso aquella que se produce entre lo que se dice en el enunciado (i) y el (v) ${ }^{14}$.

Por otro lado, es doctrina uniforme de nuestra Corte Suprema que las reglas que comprende la sana crítica corresponden a las de la lógica, las máximas de la experiencia y el conocimiento científico afianzado, en lo que se refiere al modo de apreciar las probanzas y a la adopción de las subsecuentes conclusiones ${ }^{15}$. Es así como en algunos fallos la Corte ha tenido oportunidad de explicar el contenido de cada una de esas reglas, como se presenta a continuación, de la mano de lo sostenido por la doctrina especializada...

\section{Reglas de la lógica}

La lógica, en sentido estricto, alude a reglas formales del razonamiento y no a aquello que el sentido común califica como "lo razonable". De esta forma, cuando nuestros códigos hablan de que la valoración de la prueba no podrá contradecir los principios de la lógica, ello se está refiriendo a la lógica formal y no al ámbito de lo razonable ${ }^{16}$. Es posible distinguir, dentro de las reglas básicas de la lógica, las siguientes: (i) Regla de la identidad; (ii) Regla de la no contradicción; (iii) Regla del tercero excluido; y (iv) Regla de la razón suficiente.

De forma sintética, estas reglas podrían enunciarse de la siguiente manera: (i) Identidad: cada objeto es idéntico a sí mismo; (ii) No contradicción: "Es imposible que algo sea y no sea al mismo tiempo y en el mismo sentido"; (iii) Tercero excluido: todo tiene que ser o no ser: "A es B" o "A no es B". Es necesario en este caso reconocer que una alternativa es falsa y otra verdadera y que no cabría reconocer una tercera posibilidad; y (iv) Razón suficiente: como regla fue incorporada por Leibniz y puede explicarse señalando "todo objeto debe tener una razón suficiente que lo explique". Lo que es "es" por alguna razón, "nada existe sin una causa o razón determinante" 17.

En este sentido, los enunciados de la lógica son verdaderos independientes de cualquier mundo posible, por lo que deben ser diferenciados de algunas afirmaciones

${ }^{14}$ Coloma, Rodrigo. “¿Realmente importa la sana crítica?”, en Revista Chilena de Derecho. Vol. 39 $\mathrm{N}^{\circ} 3,2012$, p. 763.

${ }^{15}$ Entre muchas otras, Rol No 3026-2010, de 25 de agosto 2011, Rol No 26.854-14 de 15 de septiembre de 2016 y Rol No 3606-15 de 17 de marzo de 2016. En esta última, lo ha declarado al analizar el artículo 128 , inciso $15^{\circ}$, de la Ordenanza de Aduanas, que igualmente consagra que la prueba en esa materia se aprecia conforme a las reglas de la sana crítica en fallo.

16 Maturana, Javier. Sana Crítica, un sistema de valoración racional de la prueba. Editorial Thomson Reuters. 2014, p. 236.

17 Navarro, René. Bases para una sana crítica. Lógica, interpretación, argumentación, máximas de la experiencia, conocimiento científico (un ensayo). RIL Editores, abril de 2014, p. 39-41. 
corrientes que usan la palabra lógica para referirse a comportamientos razonables ${ }^{18}$. Siendo entonces reglas objetivas, lo único que la lógica permite asegurar es la corrección del razonamiento y no la verdad de las conclusiones, porque solo en la medida en que el punto de partida de las premisas sea verdadero, la conclusión necesaria será verdadera al seguir las reglas de la lógica. Es por ello que la lógica por sí sola no asegura la verdad de la conclusión, ya que un razonamiento puede ser lógicamente correcto, pero llevar a una conclusión falsa, cuando las premisas de las que se parte, son también falsas ${ }^{19}$.

De manera similar ha expresado la Corte Suprema en la causa Rol N ${ }^{\circ}$ 26.854-14 de 15 de septiembre de 2016 que las reglas de la lógica ... están compuestas, en síntesis, por la regla de la identidad, mediante la cual se asegura que una cosa solo puede ser lo que es y no otra; la regla de la (no) contradicción, por la que se entiende que una cosa no puede entenderse en dos dimensiones, como ser falsa o verdadera, al mismo tiempo; la regla del tercero excluido, la cual establece que entre dos proposiciones en la cual una afirma y otra niega, una de ellas debe ser verdadera; $y$, la regla de la razón suficiente, por la cual cualquier afirmación o proposición que acredite la existencia o no de un hecho debe estar fundamentada en una razón que la acredite suficientemente. Mediante ese conjunto de reglas se asegura formalmente la corrección del razonamiento "que partiendo de premisas verdaderas arriba a conclusiones correctas" que se espera siempre tenga lugar y que, por lo demás, otorgan inequívoca objetividad a la labor de ponderación. El examen lógico formal de la argumentación del juez permite un control de la valoración que éste haya hecho de las pruebas producidas en el proceso. Por ello se afirma que la exigencia de corrección en la valoración de las probanzas de acuerdo a las reglas de la lógica constituye una verdadera garantía para aquellos que están siendo juzgados ${ }^{20}$.

Sin perjuicio de la existencia de diversas reglas de la lógica enunciadas previamente, a continuación se expresan aquellas a las que la jurisprudencia en materia tributaria se ha referido en mayor detalle.

\section{a) Regla razón suficiente}

Reiterando en la causa Rol No 12.874-15 de 7 de diciembre de 2016 que en virtud de la regla de la lógica de la razón suficiente cualquier afirmación o proposición que acredite la existencia o no de un becho debe estar fundamentada en una razón que la acredite suficientemente ${ }^{21}$, la Corte ha aclarado que basta para cumplir esta regla el que las circunstancias que se han tenido por demostradas reposen en un discurso que permite acreditarlas "suficientemente", sin que sea requisito para observar la comentada pauta de la lógica, a diferencia de lo que parece postular el

${ }^{18}$ Coloma, Rodrigo. "Panorama general de la Prueba en el Juicio Oral Chileno". En Coloma, Rodrigo, La Prueba en el Nuevo Proceso Penal, Editorial Lexis Nexis, Santiago, Chile, 2003, p. 24.

${ }^{19}$ Maturana, Javier. ob. cit., p. 236.

${ }^{20}$ En un sentido similar se explica en la causa Rol No $10.091-15$ de 23 de agosto de 2016. Ha dicho lo mismo la Corte al analizar el artículo 128, inciso $15^{\circ}$, de la Ordenanza de Aduanas, que igualmente consagra que la prueba en esa materia se aprecia conforme a las reglas de la sana crítica, en fallo Rol N ${ }^{\circ}$ 3606-15 de 17 de marzo de 2016.

${ }^{21}$ En igual orientación los fallos Rol No 21.304-14 de 5 de mayo 2015, Rol No $12.882-15$ de 8 de octubre de 2015, Rol No 8004-15 de 24 de mayo de 2016 y Rol No 10.091-15 de 23 de agosto de 2016. 
recurrente en su libelo, que semejantes conjeturas habiliten demostrarlas "inequívocamente", de modo "irrefutable" o "excluyente" de todo otro epílogo que pueda fluir de la ponderación de las mismas, de suerte que los elementos que cimentaron el desenlace alcanzado por el tribunal no soportaría, aisladamente considerados o en conjunto con otras pruebas, conducir a otro colofón diverso o contrario, sin exceder la exigencia de ajustarse a la regla de la razón suficiente y supone más bien imponer, sin ley que lo avale, un estándar de prueba a la contribuyente casi inalcanzable. Asimismo, en la causa Rol No 34.171-2015 de 22 de diciembre de 2016 se agrega que el principio de razón suficiente tiene relación con la base fáctica sobre la cual se sostiene la resolución judicial, que debe elaborarse con la información que arrojen los medios de convicción que se aporten durante el juicio, resolviendo en el caso que conoció que En ese contexto, es posible apreciar que el fallo cita los medios de prueba que le producen convicción sobre los hechos que tiene por establecidos, los que por lo demás son atingentes a esta clase de procedimientos $y$, por ende, pueden servir de sustento a los hechos de la causa y a las conclusiones que, en el orden jurídico, debe alcanzar el juez.

En cambio, en la causa Rol No $1732-15$ de 25 de enero de 2016, se indica que el principio de razón suficiente "tiene como sentido propio, declarar de un modo general qué es lo que necesita un juicio para que su pretensión de verdad no sea pretensión vacía, sino que cumplida" (Alexander Pfaender, citado en "La Sana Crítica como sistema de valoración probatoria en materia penal", Zarazo Oviedo Luis, Grupo Editorial Ibáñez, 2010, pág.96) (cons. $7^{\circ}$ ). Añade que en ese caso se cumplió con el principio en examen, cuando se cuenta con la presencia de un motivo real, aportado en el proceso judicial, que dé sustento al hecho declarado por la sentencia, en este caso, que los contribuyentes usados para la tasación de la base imponible no tienen el mismo giro que la reclamante. En esa línea de razonamiento, queda en evidencia que no se presenta la transgresión denunciada al principio de razón suficiente, desde que los juzgadores han acudido al contenido del propio acto administrativo reclamado para determinar si cumple o no con las exigencias legales, constituyendo sus menciones un elemento bastante para dar consistencia a la pretensión declarada como verdadera en el fallo, que por ello está debidamente fundado en los términos exigidos por el inciso $14^{\circ}$ del artículo 132 del Código Tributario (cons. $7^{\circ}$ ).

\section{b) Principio de no contradicción}

En el fallo Rol No $1732-15$ de 25 de enero de 2016 se declara que La no contradicción como principio lógico consiste en que no puede afirmarse a la vez y desde un mismo punto de vista y el mismo sentido que un ser es y no es (cons. $7^{\circ}$ ), expresando que en el caso de que se trató dicho principio no había sido infringido por los sentenciadores, desde que no señalan la falsedad de las facturas para luego declararlas verdaderas, sino que, sosteniendo su inefectividad, mantienen las liquidaciones que se basan en tal afirmación, y dejan sin efecto otras por un motivo distinto, a saber, que se originan en una tasación cuyas bases no cumplen con las condiciones legales (cons. $7^{\circ}$ ).

\section{Máximas de la experiencia}

Corresponden a las premisas mayores utilizadas en el razonamiento de los jueces. Si bien por sus características no pueden ser sensatamente consagradas por el legislador, constituyen una herramienta básica en el razonamiento de los jueces no obstante que 
dichas máximas no siempre se expresen. La definición de las máximas de la experiencia encuentra su origen en el célebre texto de Fiedrich Stein El Conocimiento Privado del Juez quien ha dicho que corresponden a: definiciones o juicios hipotéticos de contenido general desligados de los hechos concretos que se juzgan en el proceso, procedentes de la experiencia, pero independiente de los casos particulares de cuya observación se han inducido y que, por encima de estos casos pretenden tener validez para otros nuevos ${ }^{22}$.

Así, en la causa Rol N²996-15 de 23 de marzo de 2016, al referirse a las máximas de la experiencia, se indica que corresponde a algún criterio objetivo, interpersonal o social patrimonio del grupo social y de otras ciencias experimentales (cons. $\left.6^{\circ}\right)^{23}$.

Esta idea de objetividad debe apuntar a aquellas máximas de la experiencia cuya infracción puede ser objeto de un recurso de nulidad sustancial. Ello por cuanto solo ante la contradicción de verdaderas máximas de la experiencia es posible afirmar que existe un vicio en el razonamiento del fallo, siendo necesario distinguir las verdaderas máximas de la experiencia que se basan en generalizaciones válidas, de aquellas que basándose en generalizaciones espurias carecen de un sustento empírico.

\section{Conocimiento científicamente afianzado}

Se ha dicho que la justificación de un análisis separado de los conocimientos científicamente afianzados en relación con las máximas de la experiencia dice relación con el mayor desarrollo técnico que ha tenido la ciencia en el tiempo y su posibilidad de ofrecer una mayor garantía de confiabilidad que una máxima de la experiencia. Así, se señala que el conocimiento científicamente afianzado si bien presenta este mayor grado de confiabilidad que una máxima de la experiencia, debido a su carácter cambiante y contingente se encuentran por debajo de los principios de la lógica, que son universales, permanentes y necesarios ${ }^{24}$.

No obstante, la prueba científica y el conocimiento científicamente afianzado suele admitirse en función del apoyo que dicha forma de conocimiento provee al juzgador, dicha prueba no puede resultar en ningún caso vinculante para este, aceptándose que sea el juez quien decida si acepta los resultados o discrepa de ellos. Como indica Taruffo, cuando se afirma que el juez debe realizar una valoración autónoma acerca de la fiabilidad de la prueba científica, no se pretende que deba transformarse en un científico -lo que evidentemente sería imposible- y mucho menos que repita los análisis y experimentos que conforman la propia prueba científica. Lo que se exige es que el juez sea capaz de valorar si está en el ámbito de una forma de conocimiento dotado de dignidad y validez científica y si los métodos de investigación y control típicos de esa ciencia han sido correctamente aplicados en el caso particular que debe juzgar ${ }^{25}$.

22 Stein Friedrich. El Conocimiento Privado del Juez. Traducción por Andrés de la Oliva. Editorial Temis, Bogotá, Colombia. 1988, p. 27.

${ }^{23}$ Dentro de la jurisprudencia en materia tributaria dictada durante el 2016, no se hacen mayores referencias ni desarrollos conceptuales de las máximas de la experiencia.

${ }^{24}$ Maturana, Javier. ob. cit., p. 210.

25 Taruffo, Michele. La Prueba. Marcial Pons, 2008, p. 294. 
De esta forma, para evitar la infracción a normas reguladoras de la prueba, en relación con los conocimientos científicamente afianzados, el juez deberá expresar racionalmente su valoración, debiendo enunciar los criterios con base en los cuales ha formulado su propia interpretación y valoración de los datos y las informaciones científicas que el experto ha sometido a su atención ${ }^{26}$. Por lo anterior, el control de los tribunales superiores dice relación con determinar si se está ante un verdadero conocimiento científicamente afianzado, lo que dice relación con la verificación de la correcta aplicación de la ciencia y sus métodos cuando estos se basen en suficientes soportes empíricos y racionales.

\section{Procedencia del RECURSo de CASACIÓN EN EL FONDO POR INFRACCIÓN A LAS REGLAS DE LA SANA CRÍTICA}

La Corte Suprema, en los pronunciamientos emitidos en los procesos en los que se aplicaron las modificaciones introducidas por la Ley $\mathrm{N}^{\circ} 20.322$, que consagra la sana crítica como sistema de valoración de la prueba en materia tributaria, ha aceptado uniformemente la procedencia del recurso de casación por infracción de las reglas de la sana crítica, es así como ha señalado en la causa Rol No 26.854-14 de 15 de septiembre de 2016 (cons. $13^{\circ}$ ): Se evidencia de este modo que el sistema de sana crítica, no obstante la mayor amplitud en el margen de libertad otorgado para ponderar la prueba, impone reglas concretas y claras que no pueden ser desconocidas por los jueces al momento de utilizarlo. No es un sistema enteramente libre -y por tanto subjetivo- como el que faculta, por ejemplo, para apreciar la prueba en conciencia. En consecuencia, por constituir un sistema reglado "objetivamente" por la lógica, la experiencia y el conocimiento científicamente respaldado, su utilización por el juez es siempre controlable por esta vía.

En efecto, la norma legal que previene el sistema probatorio, así como el modo en que opera $y$ las reglas que lo componen, es de carácter sustantiva y a ella ba de adecuarse la labor de ponderación. Ello es así, porque la sola referencia de la norma al sistema de la sana crítica incorpora al precepto que lo establece a todas las reglas que la constituyen, que le son propias e indiscutibles. De ahi que siempre sea posible examinar por vía de casación su aplicación.

Verificar la adecuación del sistema de valoración probatoria a las reglas de la sana crítica no implica valorar nuevamente los hechos, pues tal labor excedería los márgenes del recurso y la competencia de este tribunal. En la especie, controlar la valoración de la prueba implica comprobar si el razonamiento jurídico del juez se ha adecuado a las reglas que impone el sistema de sana crítica; en otras palabras: examinar cómo han gravitado y qué influencia han ejercido los medios de prueba en él a la hora de arribar a la decisión que ha consignado en la sentencia. Ello fuerza a revisar la manera o forma en que se han ponderado las pruebas, más no el material fáctico de la ponderación. No se revisan los hechos, sino la aplicación del derecho, en cuanto establece la forma de ponderar, labor que ha de hacerse sin valorar. Si el inciso $14^{\circ}$ del artículo 132 del Código Tributario obliga al juez a dictar sentencia de acuerdo con estas reglas, limitando la

\footnotetext{
${ }^{26}$ Taruffo, Michele. “Ciencia y Proceso”, en Páginas Sobre Justicia Civil, Marcial Pons, 2009, p. 479.
} 
discrecionalidad del juez a la hora de valorar la prueba, el recurso de casación en el fondo no tiene otro objeto más que custodiar el respeto y la correcta aplicación de esta norma en el razonamiento que se consigna en la sentencia.

De forma tal que, solo si se logra determinar que el juez ha dado falsa o incorrecta aplicación, o derechamente ha dejado de aplicar las reglas de la sana crítica, y ello ha influido sustancialmente en la decisión, se estará en condiciones de acoger el recurso de casación en el fondo $y$ dictar, consecuentemente, sentencia de reemplazo; en la cual recién se podrán conocer nuevamente los hechos, es decir, valorar ${ }^{27}$.

Es posible mencionar que en los fallos en que se ha desestimado la infracción de alguna regla de la sana crítica, el presidente de la Sala Tributaria (Penal) de la Corte Suprema ${ }^{28}$ ha prevenido generalmente en cada uno de los fallos en que los ha participado que este tiene únicamente presente para desestimar la infracción al artículo 132, inciso $14^{\circ}$, del Código Tributario, que dicha norma no constituye una ley reguladora de la prueba, puesto que el legislador ha entregado el escrutinio probatorio en este tipo de procedimientos a la ponderación que con libertad puedan arribar los jueces de la instancia, atributo que no es revisable por la vía de la nulidad sustantiva, aparte que además los conceptos de lógica, experiencia y conocimientos afianzados se obtienen solo de manera racional y no sobre requisitos o condiciones fijadas a priori por la ley. La desatención a dichos aspectos valorativos que determinan un torcido ejercicio de la razón o sea fruto de irrealidades que deriven en falsedades o inexactitudes, devienen consecuencialmente en ausencia de fundamentos cuya sanción es la nulidad formal también perseguida en este procedimiento y que no prosperó ( $\mathrm{Rol} \mathrm{N}^{\mathrm{o}}$ 26.854-14 de 15 de septiembre de 2016). Entendiendo de esa forma que los defectos relacionados con el establecimiento de los hechos apartándose de las reglas de la sana crítica, corresponden más bien a un vicio en la exposición que realiza el fallo del establecimiento de esos hechos al no ajustarse en esa labor de motivación a las referidas reglas y, por tanto, a un defecto de fundamentación ${ }^{29}$. Esta opinión en general no ha sido seguida por el resto de los ministros

${ }^{27}$ Este criterio se encuentra igualmente en las causas Rol No $10.091-15$ de 23 de agosto de 2016, Rol $\mathrm{N}^{\circ} 13.160-15$ de 12 de septiembre de 2016 y Rol No $16.597-16$ de 29 de diciembre de 2016. Ha dicho lo mismo la Corte al analizar el artículo 128 , inciso $15^{\circ}$, de la Ordenanza de Aduanas, que igualmente consagra que la prueba en esa materia se aprecia conforme a las reglas de la sana crítica, en fallo Rol No $3606-15$ de 17 de marzo de 2016.

${ }^{28}$ El ministro Sr. Milton Juica Arancibia.

${ }^{29}$ En el mismo sentido, se puede observar una prevención idéntica por parte del ministro Sr. Juica en las causas Rol No 1522-15 de 28 de enero de 2016, Rol No 3364-15 de 22 de marzo de 2016, Rol No 800415 de 24 de mayo de 2016, Rol No 8415-15 de 28 de junio de 2016, Rol No 8109-15 de 30 de junio de 2016, Rol No 9113-15 de 13 de julio de 2016, Rol No 6184-15 de 19 de julio de 2016, Rol No 10.229-15 de 3 agosto de 2016, Rol No 14.615-15 de 8 de agosto de 2016, Rol No 16.252-15 de 5 de septiembre de 2016, Rol No 28.384-15 de 5 de septiembre de 2016, Rol No 13.160-15 de 12 de septiembre de 2016, Rol $\mathrm{N}^{\circ}$ 24.750-2015 de 11 de octubre de 2016, Rol No 18.136-2015 de 12 de octubre de 2016, Rol N 37.18115 de 29 noviembre 2016, Rol No 12.874-15 de 7 de diciembre de 2016, Rol No 34.171-2015 de 22 de diciembre de 2016 y Rol No 16.597-16 de 29 de diciembre de 2016. Acerca de esta opinión se exponen algunas consideraciones más adelante, las que dicen relación más bien con la imposibilidad de controlar las sentencias de los tribunales inferiores de aceptarse tal posición, sobre todo considerando que la ley veda el recurso de casación en la forma por la omisión de los requisitos del artículo 170 del Código de Procedimiento Civil, según se ha indicado ya previamente. 
de la Corte Suprema, quienes si bien suelen rechazar la causal de casación en el fondo por infracción a normas reguladoras de la prueba, ello obedece a otras razones diversas que se exponen en los fallos.

\section{REQUERIMIENTOS PARTICULARES DE FUNDAMENTACIÓN QUE SE DEMANDA AL RECURSO QUE DENUNCIA INFRACCIÓN A LAS REGLAS DE LA SANA CRÍTICA}

En un primer orden, la Corte, para entrar al conocimiento del fondo de la infracción al artículo 132 , inciso $14^{\circ}$, del Código Tributario, ha requerido que los arbitrios precisen las reglas de la sana crítica que el fallo impugnado habría vulnerado, no siendo suficiente una genérica alusión al quebrantamiento de las normas o principios de la sana crítica, pues esto importaría que la Corte de Casación actúe como un tribunal de instancia, lo que resulta improcedente ${ }^{30}$. Incluso ha referido en algunos fallos que el defecto expresado implica una deficiencia en la exposición de los errores de derecho por el recurso y, por esta razón, el incumplimiento de los requisitos previstos en el artículo 772 del Código de Procedimiento Civil ${ }^{31}$.

Así, en el fallo dictado en la causa Rol No 24.611-14 de 7 de enero de 2016, frente a la alegación del recurrente de que se restó valor probatorio a los informes periciales contables y financieros sin sujeción a las reglas de la sana crítica expresó, para desestimar tal reclamo, que nada señala el arbitrio respecto de la forma en que las reglas de la sana crítica fueron quebrantadas al momento de apreciar los informes periciales, ni la transgresión precisa a las pautas normativas que gobiernan la construcción de las presunciones en que habrian incurrido los sentenciadores (cons. $4^{\circ}$ ). Igualmente, en causa Rol N ${ }^{\circ} 26.854-14$ de 15 de septiembre de 2016 se sostuvo que Lo que se acaba de exponer muestra, huelga señalar, que en el arbitrio no se expresa máxima de la experiencia alguna infringida, sino solo se hace presente que conforme a un "sano, recto y desprejuiciado entender", que no es más que la apreciación subjetiva y personal del recurrente, las conclusiones alcanzadas debieron ser favorables a la reclamante (cons. $16^{\circ}$ ). Asimismo, ha declarado la Corte en la causa Rol No $12.874-15$ de 7 de diciembre

${ }^{30}$ Rol No 3606-15 de 17 de marzo de 2016: ... del análisis del recurso aparece que el recurrente nada fundamenta sobre el particular, por el contrario, se limita a sustentar la impugnación en la valoración de la prueba efectuada por los sentenciadores, y no en la vulneración de las leyes de la lógica o de las máximas de la experiencia y del conocimiento científicamente afianzado (...) Por lo precedentemente expuesto, atendido que no compete a esta Corte ponderar probanzas, se está ante la obligación de desestimar el presente capítulo de impugnación (cons. $6^{\circ}$ ). De igual forma, en causas Rol No 6327-15 de 28 de junio de 2016, Rol No 13.160-15 de 12 de septiembre de 2016 y Rol No $18.136-2015$ de 12 de octubre de 2016.

${ }^{31}$ Rol No 1961-15 de 23 de marzo de 2016: Así las cosas, las graves omisiones constatadas en el planteamiento de este capítulo del recurso importan el incumplimiento de los extremos contenidos en los ordinales $1^{\circ}$ y $2^{\circ}$ del artículo 772 del Código de Procedimiento Civil, motivo ya suficiente para desestimar la infracción de las reglas de la sana crítica en la forma planteada en el arbitrio (cons. $3^{\circ}$ ). También en ese orden Rol N ${ }^{\circ} 2996-15$ de 23 de marzo de 2016 y Rol No 28.384-15 de 5 de septiembre de 2016. En la causa Rol No 7424-16 de 11 de julio de 2016 se expuso que el artículo 132, inciso $14^{\circ}$, si bien establece la sana crítica como sistema de apreciación de la prueba, no ha consignado el arbitrio qué regla específica fue la vulnerada, de qué forma y en relación a qué medio probatorio, por lo que en esta parte el libelo carece de la fundamentación que permita siquiera entrar al estudio de la infracción denunciada. 
de 2016 Que el inciso catorce del artículo 132 entroniza la sana crítica como método de valoración de la prueba en este procedimiento, pero el libelo no precisa ninguna regla reguladora de la prueba concreta de aquellas que componen dicho sistema $y$, consecuencialmente, no desarrolla ni funda como se produce la transgresión de las mismas, razón suficiente para desestimar esta porción del arbitrio (cons. $15^{\circ}$ ). En el mismo sentido en la causa Rol No $10.091-15$ de 23 de agosto de 2016 se ha declarado que el recurso de casación en el fondo no puede prosperar si se limita a sustentar la impugnación en la supuesta falta de ponderación de la prueba efectuada por los sentenciadores, y no en una concreta y determinada vulneración de las leyes de la lógica que reclama. En tal sentido, del análisis del recurso fluye que siguiendo el mismo esquema de razonamiento desarrollado por el fallo, esto es, partida por partida, construye la impugnación aludiendo en detalle -según cada partida- a medios de prueba en particular a los cuales atribuye mérito de convicción relevante para sustentar su reclamo, nada de lo cual fue compartido por los sentenciadores del grado, lo que según los motivos que anteceden, escapa de los márgenes del presente remedio procesal dirigido a velar por la correcta aplicación de las leyes llamadas a dirimir el conflicto y no en convertirse en una nueva instancia donde las partes busquen una diferente ponderación o apreciación de las pruebas aportadas al proceso en procura de obtener un pronunciamiento que modifique lo resuelto por los jueces del fondo, quienes en la especie, según se explicó, resolvieron el conflicto actuando legítimamente en el marco entregado por la ley para apreciarlas o valorarlas (...) Así las cosas, atendido que lo postulado a título de transgresión al funcionamiento del sistema de sana crítica no es más que una mera valoración de la prueba rendida no compete a esta Corte, pues tal función es privativa de los tribunales del fondo, por lo que el recurso que se viene analizando no puede prosperar (cons. $5^{\circ}$ y $\left.6^{\circ}\right)^{32}$.

Adicionalmente al extremo antes referido, la Corte Suprema ha venido señalando que no basta que se denuncie la infracción de alguna específica regla de la sana crítica para que el recurso de casación que la postula sea acogido, sino que además debe precisarse qué determinada prueba fue la erróneamente valorada, esto es, qué documento o testimonio, por ejemplo, y qué regla de la sana crítica respecto de esa probanza imponía a los jueces concluir o establecer los hechos en la forma que interesa al recurrente de establecerse la infracción al valorar determinada prueba, única forma en que la acusada infracción tenga influencia sustancial en lo dispositivo del fallo.

32 Desestimando igualmente la infracción a las reglas de la sana crítica por no expresar la específica regla vulnerada, v. causas Rol No 1522-15 de 28 de enero de 2016, Rol No 3606-15 de 17 de marzo de 2016, Rol No 3364-15 de 22 de marzo de 2016, Rol No 1961-15 de 23 de marzo de 2016, Rol No 2996-15 de 23 de marzo de 2016, Rol No 3364-15 de 22 de marzo de 2016, Rol No 1474-15 de 4 de abril de 2016 , Rol N ${ }^{\circ}$ 2866-2015 de 21 de abril de 2016, Rol N $7092-2015$ de 25 de abril de 2016, Rol No $9432-15$ de 24 de mayo de 2016, Rol No 6327-15 de 28 de junio de 2016, Rol N $7.852-15$ de 6 de julio de 2016, Rol $\mathrm{N}^{\circ}$ 7424-16 de 11 de julio de 2016, Rol No 8.815-15 de 12 de julio de 2016, Rol N $\mathrm{N}^{\circ} 14.912-15$ de 1 de agosto de 2016, Rol No 8314-2015 de 2 de agosto de 2016, Rol No 10.229-15 de 3 agosto de 2016, Rol $\mathrm{N}^{\mathrm{o}}$ 14.615-15 de 8 de agosto de 2016, Rol No 20.174-15 de 8 de agosto de 2016, Rol No $16.252-15$ de 5 de septiembre de 2016, Rol No 10.361-15 de 12 septiembre de 2016, Rol No 26.652-2015 de 6 de octubre de 2016 y Rol No 16.597-16 de 29 de diciembre de 2016. No obstante, en algunas ocasiones, pese a no precisarse las reglas de la lógica y máximas de la experiencia supuestamente vulneradas, la Corte analiza el fallo para demostrar que no hay infracción, así en el Rol No 9113-15 de 13 de julio de 2016. 
Respecto del primer punto, se ha señalado en la causa Rol No $10.174-15$ de 2 de junio de 2016, que los sentenciadores cuestionados no podrían haber errado en la aplicación de la norma comentada en la forma que postula el recurrente, pues si la protesta consiste en que prescindieron de prueba legalmente admisible y legalmente introducida al juicio por la parte reclamante, se debió invocar entonces -lo que no se hizo- la infracción de las disposiciones de los Códigos Civil, de Procedimiento Civil y Tributario que precisamente declaran admisibles los medios de prueba supuestamente descuidados, y no solo eso, pues para que dicha omisión tuviera alguna incidencia en lo dispositivo del fallo observado, era menester igualmente que la ley reservara para tales probanzas el valor de plena prueba, de modo que supusiera para los jueces el deber de tener por cierto los hechos de que dan cuenta, cuestión que en el presente procedimiento no puede darse atendido que el artículo 132, inciso $14^{\circ}$, del Código Tributario prescribe que la prueba debe apreciarse de conformidad a las reglas de la sana crítica, sin tasar anticipadamente-salvo situaciones excepcionales que no se aplican al caso en estudio- el valor que se dará a los medios probatorios rendidos por las partes (cons. $5^{\circ}$ ).

En cuanto al segundo asunto, es importante mencionar que incluso de valorarse erróneamente un determinado medio probatorio, ello en general no importa necesariamente un cambio en los hechos establecidos por el tribunal -lo que, por tanto, lleva al recurso a ser rechazado por falta de influencia sustancial en lo dispositivo del fallo-, debido a que las conclusiones fácticas que alcanza el juez suelen ser el resultado de la apreciación de un conjunto de elementos, a base de estos se van progresivamente construyendo las premisas -o presunciones judiciales, si se quiere- en el que, conforme a su multiplicidad, gravedad, precisión, concordancia y conexión -criterios que precisamente el artículo 132 , inciso $14^{\circ}$, del Código Tributario impone al tribunal tomar en especial consideración- finalmente se asientan los hechos que sirven para la decisión del asunto. De ese modo, incluso un error al desestimar el valor de determinado documento o testigo no necesariamente llevaría a cambiar los hechos asentados por el tribunal si existían otros antecedentes de suficiente peso y concordancia para mantener sus asertos fácticos. En esa línea se ha explicado en la causa Rol No 26.854-14 de 15 de septiembre de 2016 que respecto de la influencia sustancial de la errónea aplicación de las reglas de la sana crítica en lo dispositivo del fallo impugnado cabe primero apuntar que las conclusiones que alcanza el tribunal sobre este asunto no es el resultado de la valoración de un solo medio probatorio o el corolario la apreciación de un solo becho establecido como premisa de sus conclusiones, sino que la decisión a que arriba se alcanza luego de analizar distintos medios probatorios aportados por ambas partes, e ir estableciendo diversos hechos, circunstancias o elementos aislados que luego, ponderados en su conjunto y globalmente, le llevan a determinar que no se acreditó haber dado cumplimiento a los supuestos y requisitos para la determinación de la vida útil de los bienes depreciados.

La consideración anterior conlleva que el constatar que el tribunal incurrió en un error en la aplicación de alguna regla de la sana crítica al establecer uno o más hechos, circunstancias o elementos del universo de aquellos que el tribunal ponderó para alcanzar la conclusión sobre la falta de acreditación del punto controvertido, no conlleva necesariamente que la conclusión final del tribunal deba variar, si no se demuestra que en la apreciación de otros medios probatorios y en el establecimiento de los otros hechos que sirvieron de premisas a sus asertos finales, se ha incurrido igualmente en el mismo error, sin lo cual, entonces, el recurso carece de influencia sustancial 
en lo dispositivo del fallo (....) incluso de tenerse el segundo informe de Michaelsen Saffer como auténtico y de fecha cierta, de ello no se deriva necesariamente que el tribunal deba entonces tener por demostrada la vida útil de los bienes objeto de ese informe, pues contra tal conclusión se mantienen los otros distintos cuestionamientos a ese instrumento, principalmente referidos a la falta de concordancia con el resto de la documentación contable y declaraciones de la reclamante, así como a la falta de conocimientos de Michaelsen Saffer para referirse al estado de conservación y vida útil de las maquinarias $y$, por consiguiente, por no baberse apoyado en un informe técnico para salvar esas deficiencias (cons. $14^{\circ}$ y $16^{\circ}$ ).

Engarzado a lo anterior, incluso de aceptarse la infracción de una determinada regla de la sana crítica al no tener por demostrado el fallo un determinado hecho, ello no importa que, a contrario sensu, entonces necesariamente deba darse por acreditado el hecho en que se basan las pretensiones de la parte recurrente. Así ha dicho la Corte en causa Rol No 1961-15 de 23 de marzo de 2016 que ...el recurso tampoco explicita cómo esas reglas de la sana critica -que no se detallan-correctamente aplicadas habrían llevado necesaria y perentoriamente a los jueces a concluir lo que interesa al recurrente-explicación insoslayable atendida la carga de la prueba que pesa sobre el contribuyente de desvirtuar las impugnaciones de las liquidaciones-, única manera que la infracción de esas reglas tuviera influencia sustancial para lo dispositivo del fallo (cons. $3^{\circ}$ ). Asimismo, en el recién citado fallo pronunciado en la causa Rol No 26.854-14 de 15 de septiembre de 2016 se expone que: en este procedimiento de reclamación es la contribuyente la que tiene la carga probatoria, conforme al artículo 21, inciso $2^{\circ}$, del Código Tributario, de lo que se deriva que, incluso de ser efectivos los errores en la aplicación de las reglas de la sana crítica que se denuncian infringidas en la valoración de determinados medios de prueba o en el establecimiento de determinados hechos que sirven de premisas a las conclusiones finales de los jueces de la instancia en relación a este asunto, ello no conlleva, a contrario sensu, que los jueces, de aplicar correctamente esas reglas, debieron entonces concluir el hecho o circunstancia que interesa al reclamante, esto es, que la vida útil de los bienes aportados corresponde a aquella que sirvió de base a la depreciación utilizada como gasto en los años tributarios 2010 y 2011. En efecto, de haber incurrido en algún error los sentenciadores, por ejemplo, al restar valor al peritaje de Michaelsen Saffer por su falta de fecha cierta, el constatar dicho error no conlleva por mandato legal entonces que los jueces hayan debido tener por ciertos los datos que sobre la vida útil de los bienes entrega dicho peritaje, menos aún si esa información no es concordante con el resto de los antecedentes, como detalladamente explica el fallo (cons. $\left.14^{\circ}\right)^{33}$.

33 Destacando el mismo aspecto, esto es, que el recurso de casación no explicita cómo las reglas de la sana crítica correctamente aplicadas habrían llevado necesaria y perentoriamente a los jueces a concluir lo que interesa al recurrente, única manera que la infracción de esas reglas tuviera influencia sustancial para lo dispositivo del fallo, v. Rol No 2996-15 de 23 de marzo de 2016, Rol N 1474-15 de 4 de abril de 2016, Rol N $N^{\circ} 10.174-15$ de 2 de junio de 2016 y Rol No $10.241-15$ de 1 de junio de 2016. En este último fallo se señala que para que la infracción de las reglas de la sana crítica conlleve la invalidación del fallo se requiere, además, que esa infracción tenga influencia sustancial en lo dispositivo del fallo. En el caso de las reglas de la sana crítica, y dada la carga de la prueba que recae en el Servicio en este procedimiento como ya se mencionó, ello supone que cada una de las máximas de la experiencia o reglas de la lógica supuestamente quebrantadas -o al menos una de ellas-, de ser aplicada correctamente, necesaria y perentoriamente "debe" -y no solo puede-llevar a los sentenciadores a concluir el actuar malicioso del contribuyente denunciado, situación que no se presenta en el caso sub judice $\left(\right.$ cons. $\left.3^{\circ}\right)$. 


\section{DistinCión ENTRE INFRACCIONES A LAS REGLAS DE LA SANA CRÍTICA Y DEFECTOS DE FUNDAMENTACIÓN DEL FALLO}

Como se ha venido explicando, de acuerdo con el criterio de la Corte, el que por disposición del artículo 768, inciso $2^{\circ}$, del Código de Procedimiento Civil en relación con lo previsto en el inciso $2^{\circ}$ del artículo 766 del mismo código, no resulte procedente el recurso de casación en la forma por la causal del $\mathrm{N}^{\circ} 5$ del citado artículo 768 en relación con el artículo $170 \mathrm{~N}^{\circ} 4$, por la omisión de las consideraciones de hecho o de derecho que sirven de fundamento a la sentencia, no puede significar, o llevar a aceptar que tales deficiencias de fundamentación, de naturaleza ordenatorio litis, se hagan valer y se pretenda su corrección vía el recurso de casación en el fondo.

En esa línea, la Corte Suprema se ha preocupado de aclarar que si bien el artículo 132 luego de señalar que La prueba será apreciada por el Juez Tributario y Aduanero de conformidad con las reglas de la sana crítica dispone que Al apreciar las pruebas de esta manera, el tribunal deberá expresar en la sentencia las razones jurídicas y las simplemente lógicas, científicas, técnicas o de experiencia en virtud de las cuales les asigna valor o las desestima. En general, tomará en especial consideración la multiplicidad, gravedad, precisión, concordancia y conexión de las pruebas o antecedentes del proceso que utilice, de manera que el examen conduzca lógicamente a la conclusión que convence al sentenciador, con este último párrafo no se añaden reglas de la sana crítica diversas a las antes mencionadas -de la lógica, máximas de la experiencia y conocimiento científicamente afianzado-, sino simplemente se establecen deberes y orientaciones en materia de fundamentación del establecimiento de los hechos, de modo que la sentencia deba expresar las razones jurídicas y las reglas de la sana crítica conforme con las que asigna o desestima el valor de las probanzas, así como debe, en general, tomar los elementos que indica la citada disposición al expresar la valoración de la prueba realizada. Así, en causa Rol No 8318-15 de 16 de mayo de 2016, la Corte ha sentenciado que En relación al artículo 132, inciso $14^{\circ}$, del Código Tributario, el recurrente no alega, ni justifica, la infracción de una regla de la sana crítica que, además, tenga influencia sustancial en lo dispositivo del fallo, sino solo cuestiona la desatención del fallo de los criterios - multiplicidad, gravedad, precisión, concordancia y conexión - que la ley impone tomar en "especial consideración" al juez al expresar en la sentencia las razones jurídicas y las simplemente lógicas, científicas, técnicas o de experiencia en virtud de las cuales les asigna valor a la prueba o las desestima, es decir, lo alegado constituye un defecto de fundamentación u ordenatorio litis, y no sustantivo que pueda ser remediado mediante el recurso de casación en el fondo impetrado (cons. $\left.7^{\circ}\right)^{34}$.

Mientras, en causa Rol No 1961-15 de 23 de marzo de 2016, se indicó que En lo concerniente al artículo 132, inciso 14, del Código Tributario, el arbitrio realiza diversos cuestionamientos que dicen relación con la defectuosa fundamentación del fallo mas no con la infracción de concretas reglas de la sana crítica, es así como en todo el recurso sólo se menciona como específica regla vulnerada el "principio de razón suficiente", pero al momento de explicar la

${ }^{34}$ En igual orientación, Rol No 10.241-15 de 1 de junio de 2016, Rol N ${ }^{\circ} 10.048-15$ de 11 de julio de 2016, Rol No 14.912-15 de 1 de agosto de 2016, Rol No 20.174-15 de 8 de agosto de 2016 y Rol $\mathrm{N}^{\mathrm{o}} 28.384-15$ de 5 de septiembre de 2016. 
forma en que se produce su quebrantamiento nuevamente se arguyen defectos en la motivación del fallo - "solo llega a conclusiones, sin indicar los medios probatorios ni las razones por las cuales les asigna o resta valor"-, vicios formales que no pueden ser enmendados por el recurso de casación en el fondo interpuesto (cons. $\left.3^{\circ}\right)^{35}$.

Igualmente, en el fallo dictado en la causa Rol No 26.854-14 de 15 de septiembre de 2016 se determina que un atento examen de las infracciones denunciadas a las reglas de la sana crítica en relación a este punto -vida útil de los bienes-, demuestra, primero, que ellas no son tales, sino que en su mayoría se trata de reclamos por falta de análisis de la prueba, lo que constituye un defecto de carácter ordenatorio litis cuyo conocimiento y enmienda no es propio del recurso de casación en el fondo, como lo demuestra que las mismas alegaciones sean el sustento del recurso de casación en la forma... Que, en primer término, refiere el arbitrio que el fallo de segunda instancia no se habría becho cargo de prueba tocante a la vida útil de los bienes, aludiendo al Informe de Michaelsen Saffer, declaración jurada del mismo, listado de activo fijo, corrección monetaria y depreciación del activo físico de la reclamante para los años 2008 a 2012, anexos 1 a 4 sobre los bienes aportados vigentes y obsoletos. Pues bien, resulta de claridad meridiana que aqui se cuestiona la falta de valoración de esos documentos y no su errónea valoración, es decir, la falta de exposición de las razones por las cuales no se estimó útil dicha prueba para acreditar la vida útil de los bienes, cuestión que ya se ha dicho, constituye un defecto de carácter ordenatorio litis no susceptible de enmendar mediante el recurso de casación en el fondo (cons. $15^{\circ}$ y $16^{\circ}$ ).

Sin embargo, hay fallos aislados en que la Corte sí parece entender las infracciones a la sana crítica, como defectos de fundamentación, en particular cuando se trata del principio de razón suficiente. Así por ejemplo, en causa Rol No 4.879-15 de 21 de enero de 2016, frente a la alegación de que se quebrantan las reglas de la sana crítica al haberse incurrido en omisión de valoración de toda la prueba acompañada, la Corte la descarta no por no corresponder ella a una infracción a las referidas reglas, sino que se aboca a demostrar que el fallo impugnado sí valora la prueba, al señalar que La prueba rendida impidió al tribunal verificar las operaciones declaradas como costos y gastos. Los créditos invocados corrieron la misma suerte. Ello, dada su insuficiencia, por una parte, y, al mismo tiempo, por extenderse en términos generales que no bicieron posible establecer el vínculo entre los instrumentos acompañados y los hechos de la controversia, es decir las operaciones realizadas. Tales conclusiones descartan la denuncia de infracción a los artículos 17, 21 y 86 del Código Tributario y a las reglas de la sana crítica (cons. $\left.5^{\circ}\right)^{36}$.

Finalmente es admisible reiterar que, al decir relación las reglas de la sana crítica solo con la valoración o ponderación de la prueba, los errores que en relación con ellas se denuncien únicamente pueden versar acerca del erróneo establecimiento de los hechos,

${ }^{35}$ De la misma manera en Rol No 3364-15 de 22 de marzo de 2016 se expresó que se cuestiona la valoración y consideración de la prueba rendida en la fundamentación del fallo, lo que corresponde a un defecto formal que no puede ser corregido mediante el recurso de casación en el fondo impetrado (cons. $9^{\circ}$ ). También $\mathrm{Rol} \mathrm{N}^{\circ} 3266-15$ de 18 de abril de 2016, Rol No 8214-15 de 24 de mayo de 2016, Rol No 9432-15 de 24 de mayo de 2016 y Rol N $11.183-15$ de 30 de junio de 2016.

${ }^{36}$ Similar proceder se observa en los fallos dictados en las causas Rol No $30.320-14$ de 25 de enero de 2016, Rol No 8415-15 de 28 de junio de 2016 y Rol No 42-16 de 29 de noviembre de 2016. 
mas no por otro tipo de errores jurídicos, ya sea en la interpretación o aplicación de normas sustantivas ${ }^{37}$ o procesales ${ }^{38}$, o en el desarrollo de las disquisiciones jurídicas que resulten contradictorias ${ }^{39}$, excedan el objeto de lo debatido, etcétera ${ }^{40}$.

${ }^{37}$ En causa Rol No 3266-15 de 18 de abril de 2016 se declaró que en lo concerniente a la infracción al inciso $14^{\circ}$ del artículo 132 del Código Tributario, que consagra la sana crítica como sistema de valoración probatorio, el recurrente sólo sustenta dicha infracción en errores jurídicos sobre distintos conceptos del orden tributario así como en la insuficiente fundamentación del fallo en la valoración de la prueba, no correspondiendo ninguno de dichos asuntos a la infracción denunciada, puesto que respecto de los errores jurídicos ellos no dicen relación con la valoración de las probanzas sino con el acertado entendimiento de asuntos jurídicos, de manera que si alguna equivocación se cometió sobre ese punto, debió esgrimirse la respectiva infracción de ley (cons. $9^{\circ}$ ).

38 En la causa Rol N $\mathrm{N}^{\circ}$ 7257-2015 de 19 de julio de 2016 se arguye en el recurso que se vedó al contribuyente la posibilidad de rendir prueba para demostrar que no experimentó un incremento patrimonial que justifique la liquidación reclamada, circunstancia que enlazó con la garantía constitucional a un justo y racional procedimiento, resolviendo la Corte que dicho reclamo no constituye una causal de nulidad sustantiva que pueda fundar un recurso como el interpuesto, sino más bien configura un motivo de casación de forma relativo a una carencia en la ritualidad procesal que, en concepto del recurrente, le provocó perjuicio. Tal arbitrio no ba sido interpuesto por la reclamante, motivos por los cuales la referida argumentación no será analizada, y con ello se desechará la pretendida infracción del artículo $19 \mathrm{~N}^{\circ} 3$ de la Constitución Política de la República (cons. $5^{\circ}$ ). En la causa Rol N $14.912-$ 15 de 1 de agosto de 2016, por su parte, se explica que, respecto de la alegación de infracción del principio de bilateralidad de la audiencia por revisar el fallo solo la prueba de la reclamada, ello constituye un defecto de carácter ordenatorio litis que no puede ser conocido ni enmendado mediante el recurso de casación en el fondo que dice relación con la errónea aplicación del derecho (cons. $7^{\circ}$ ). Y en la causa Rol No 37.181-15 29 noviembre 2016 se refirió que debe rechazarse la infracción que se acusa al artículo 132, inciso 14, del Código Tributario, pues la sentencia no descuida los criterios que deben ponderarse para discernir una eventual infracción al derecho a ser juzgado en un plazo razonable, como ha sido demostrado, sin perjuicio que las alegaciones que sustentan esta parte del recurso no pueden llegar a constituir la infracción de una norma reguladora de la prueba, desde que se trata de meras diferencias del recurrente respecto a la valoración de los elementos que los sentenciadores consideraron para adoptar la decisión impugnada y al cuestionamiento a la falta de análisis de otras circunstancias -ni siquiera fijadas en el fallo, como extravío de antecedentes y otras dificultades probatorias-, alegación esta última que además tiene un carácter ordenatorio litis y que, por ende, no puede ser conocida y enmendada mediante el recurso de casación deducido (cons. $12^{\circ}$ ).

${ }^{39}$ Por ejemplo, en la causa Rol No 36.489-15 de 24 de octubre de 2016, en lo concerniente a la alegada contradicción que se apreciaría entre algunos de los considerandos y lo resolutivo de la sentencia -en cuanto a expresar que no habrá pronunciamiento sobre el fondo y luego resolver la devolución de las sumas solicitadas-, la Corte expresó que esa materia no tiene relación con la errada o falta de aplicación de una regla de la sana crítica al valorar un determinado o un conjunto de probanzas, sino con ... una supuesta contradicción entre lo decidido en la sentencia y lo señalado en su parte considerativa, defecto en definitiva, igualmente de carácter ordenatorio litis, ninguno de los cuales puede ser conocido ni enmendado mediante el recurso de casación en el fondo deducido $\left(\right.$ cons. $\left.5^{\circ}\right)$. También en Rol No 6.184-15 de 19 de julio de 2016, donde se realizan diversos cuestionamientos al fallo que no dicen relación con la equivocada aplicación de las reglas de la sana crítica, declarando el fallo Que en cuanto a la infracción al artículo 132 inciso $14^{\circ}$ del Código Tributario hay que tener presente que de todos los yerros que atribuye el arbitrio a la sentencia en este punto el único que dice relación concreta a una regla de la sana crítica es aquel que se refiere a la infracción al principio de la no contradicción presuntamente cometida en los razonamientos $8^{\circ}$ y $12^{\circ}$ de la sentencia. Sin embargo, no es posible concluir como lo hace el recurrente la existencia del referido error puesto que en el motivo $8^{\circ}$ de la sentencia se realiza un análisis general de la normativa que resulta aplicable para determinar el derecho a la devolución por saldo a favor originado en PPM y en el motivo $12^{\circ}$ se hace un análisis específico en relación a la controversia en particular que resulta focalizado solo a la efectividad de las retenciones de honorarios hechas por el contribuyente, el que se complementa con los motivos siguientes que abordan el cúmulo de razones que explican y sustentan la decisión arribada por los jueces del fondo (cons. $8^{\circ}$ ).

${ }^{40} \mathrm{Sin}$ embargo, en algunas ocasiones la Corte, no obstante no tratarse los errores invocados en el recurso de aquellos que digan relación con la valoración de la prueba y el subsecuente establecimiento de hechos, 


\section{El CONTROL DE LA MOTIVACión MEDiANTE LA CASACióN EN EL FONDO COMO CONDICIÓN NECESARIA DE UN SISTEMA DE VALORACIÓN RACIONAL DE LA PRUEBA}

Como ya se explicó, la sana crítica ha sido definida como aquel sistema de valoración de la prueba en que el juez aprecia libremente la prueba atendiendo a criterios objetivos, los que se encuentran sujetos a parámetros racionales como la lógica, las máximas de la experiencia y los conocimientos científicamente afianzados ${ }^{41}$, debiendo fundamentar su valoración mediante la exposición de las razones que ha tenido en consideración para estimar o desestimar cada una de las pruebas aportadas por las partes ${ }^{42}$, por lo que está obligado a cumplir con tres condiciones esenciales: i) racionalidad y objetividad en la valoración; ii) valoración discrecional dentro de ciertos parámetros racionales genéricos y iii) fundamentación ${ }^{43}$. El examen de este tercer punto resulta de especial trascendencia, debido a la exclusión legal de la correspondiente causal de casación en la forma, como ya se ha mencionado. Un punto de partida dice relación con que un sistema de valoración racional de la prueba solo tiene sentido y puede existir en la medida en que la sentencia, en su calidad de documento que consigna la valoración de los distintos elementos probatorios, explicite cuál ha sido el razonamiento lógico por el que se ha llegado a un resultado determinado. Lo contrario impediría determinar si efectivamente se ha realizado un proceso racional para la valoración de esta prueba, pudiendo construirse la sentencia

igualmente se aboca a desestimar los errores alegados analizando el fondo de la protesta del recurrente. Por ejemplo, en causa Rol No 8.109-15 de 30 de junio de 2016, donde se cuestiona el que la sentencia no haya apreciado las pruebas rendidas al considerarlo innecesario al tenor de otro pronunciamiento previo emitido en el mismo fallo, respecto de ello se alega infracción a la lógica porque dicho pronunciamiento no era parte de la controversia ni materia de la apelación del reclamante, lo que llevaría a concluir que las pruebas fueron desestimadas sobre la base de un presupuesto jurídico incorrecto, declara la Corte que tal razonamiento descansa en el error de dar por cierto que el pronunciamiento del fallo impugnado acerca de la validez de las resoluciones que fundan los cargos por tasa no son parte del asunto controvertido lo cual ya fue desestimado en esta sentencia al resolver respecto de la casación formal en el considerando sexto precedente, por lo que no es posible apoyar en tal argumentación infracción alguna a las reglas de la lógica al resultar errada la premisa en que se sostiene. Igualmente en la causa Rol N ${ }^{\circ}$ 991-15 de 2 de agosto de 2016, aunque se discute en el recurso los alcances de la norma sustantiva del artículo 35 de la Ley sobre Impuesto a la Renta, lo que se presenta como un error en la aplicación de las reglas de la sana crítica, la Corte se hace cargo de esa alegación en vez de desestimar que pudiera haber allí una infracción a las referidas reglas: El recurrente sostiene que los sentenciadores le estarían exigiendo más requisitos al artículo 35 de la ley de impuesto a la renta que los que en ella se expresa y en eso consistiría el error y lo mismo sería respecto a la fundamentación del error del artículo 132 inciso 14 del Código Tributario, la facultad establecida en favor de la administración tributaria, supone o tiene implícito el requisito, que los contribuyentes con que se obtiene el promedio y que giren en la misma actividad o en la misma plaza, tienen que ser parecidos, equivalentes o comparables $y$ de acuerdo a lo señalado anteriormente no lo es si comparamos instituciones con o sin fines de lucro, justamente para establecer las ganancias de ellas (cons. 5º). v.t. Rol No 24.750-2015 de 11 de octubre de 2016.

${ }^{41}$ Couture ha señalado que se trataría de una categoría intermedia entre un sistema de prueba legal tasada y un sistema de íntima convicción, con una regulación sobre la actividad intelectual del juez frente a la prueba. Couture, Eduardo. Fundamentos de Derecho Procesal Civil. Ediciones Depalma, 1985, p. 276.

42 En este sentido Horvitz, María Inés y López Julián. Derecho Procesal Penal. Editorial Jurídica de Chile. Santiago, 2004, Tomo II, p. 150.

43 Maturana, J. ob.cit., p. 107. 
más bien en un sistema de íntima convicción del juez, cuyo razonamiento perfectamente podría prescindir de la prueba para fundamentarse en razones de otra índole ${ }^{44}$. Esto último no se condice con un sistema de valoración racional que requiere precisamente de la actividad del juez frente a la prueba, permitiendo a su vez un control respecto de dicha valoración ${ }^{45}$. Por lo anterior, tal falta de externalización constituiría en sí misma una causal de nulidad de la sentencia por infracción de normas reguladoras de la prueba ${ }^{46}$.

Asimismo y según enseña Maturana, refiriéndose de manera general al control mediante el régimen de recursos respecto de la obligación de fundamentación, este no solo procede cuando ella es inexistente, sino también cuando resulta insuficiente, toda vez que la suficiencia es precisamente una condición esencial que también forma parte del concepto mismo de sana crítica $^{47}$, debiendo por tanto el juez referirse a cada una de las pruebas y señalar bajo parámetros racionales los motivos por los que las acepta o las desestima.

En ese contexto, parece que el recurso procesal idóneo para controlar dicha infracción por insuficiencia en materia tributaria es precisamente el recurso de casación en el fondo, el que si bien es de derecho estricto y no se considera instancia, admite como excepción a la revisión de los hechos del proceso la existencia de alguna infracción a las normas reguladoras de la prueba ${ }^{48}$, como es el caso del inciso 14 del artículo 132 del Código Tributario, cuyos criterios jurisprudenciales ya se han expuesto latamente.

Un problema particular en materia tributaria dice relación con que los recursos de casación en el fondo interpuestos por infracción a las normas reguladoras de la prueba en esta área, la mayoría de ellos dice relación con los denominados juicios de acreditación (utilizándose este concepto en el sentido de la acreditación de los resultados de cuentas contables del Libro Mayor o del resultado de cuentas de balance por medio de contabilidad completa y sus respectivos respaldos, para dar cuenta de la revisión de actos administrativos cuya impugnación obliga a una alta actividad probatoria por parte del contribuyente en términos de volumen de documentación), por lo que habitualmente se requiere de la revisión de una gran cantidad de documentos de respaldo para verificar la correcta determinación de los impuestos, lo que podría tener directa conexión con el extensivo rechazo de los arbitrios interpuestos por esta causal.

${ }^{44}$ Que prescindiría más bien de un razonamiento cognoscitivo frente a la prueba. GASCón, Marina. Los hechos en el derecho: Bases argumentales de la prueba. Segunda edición, editorial Marcial Pons, Madrid, España, 2004, p. 98.

45 Taruffo, Michele. La prueba de los hechos. Editorial Trotta. Traducción de Jordi Ferrer Beltrán, Madrid, España, 2002, p. 403.

${ }^{46} \mathrm{Al}$ respecto se ha señalado: "La exigencia de fundamentación solo puede tener un contenido concreto en la medida que exista un medio de control de la misma, puesto que de otra manera, el mandato que hace la ley al juez de ceñirse a ciertas restricciones en la valoración de la prueba y de fundar la sentencia, carecería completamente de sentido si no existiera luego la posibilidad de un control de la sentencia mediante el régimen de recursos" (énfasis agregado). Ascencio, Félix. Revisión de los hechos y recursos de nulidad. Memoria para optar al grado de Licenciado en Ciencias Jurídicas y Sociales, Universidad de Chile. Santiago, 2005 , p. 8.

${ }^{47}$ Maturana, J. (2014), ob. cit., p. 120.

${ }^{48}$ Mosquera, Mario y Maturana, Cristián. Los Recursos Procesales. Editorial Jurídica de Chile, 2013, pp. 295-296. 
Lo anterior, más allá de la incorrecta utilización del recurso de casación como una tercera instancia forzada sin que exista una infracción a las normas reguladoras de la prueba, supone que para su correcta verificación, el control del sentenciador del tribunal de casación implicaría la revisión de todos los antecedentes o medios probatorios aportados hasta antes de la vista de la causa. Esta dificultad práctica de revisión de la prueba deriva habitualmente de la naturaleza de los documentos a indagar, principalmente de naturaleza contable, así como del volumen o cantidad de los instrumentos de respaldo de aquellos, lo que, si bien no excusa al sentenciador de realizar la revisión respectiva y someterse a la norma de control de la prueba conforme a las reglas de la sana crítica -debiendo por tanto fundar su decisión de forma suficiente y completa-, es una situación forense que no puede ser desconocida y que sin duda incide directamente en la extensión y profundidad de la fundamentación de la sentencia.

Ahora bien, la presentación de una gran cantidad de documentación al juicio por el reclamante deriva de la norma general relativa a carga de la prueba en materia impositiva, contenida en el artículo 21 del Código Tributario, que obliga al contribuyente a acreditar la correcta determinación de su resultado tributario basado en su contabilidad fidedigna, entendiéndose esta como el reflejo fiel y cronológico de la realidad en las operaciones realizadas por este en sus libros contables y con sus respectivos respaldos ${ }^{49}$. Por ello, no es infrecuente que el contribuyente deba aportar gran volumen de antecedentes en casos en que se le ha emitido una liquidación en los términos del artículo 24 del Código Tributario o se le ha denegado una devolución de impuestos por el resultado de un periodo específico, existiendo incluso casos en los que se les revisa la determinación de una pérdida tributaria desde su origen ${ }^{50}$.

Sin embargo, tanto el carácter técnico de la prueba aportada como su volumen no puede en ningún caso significar una excusa para debilitar el sistema de valoración racional de la prueba dispuesta por el legislador, exonerando de un control por la vía de los recursos procesales dichas infracciones. Ello implicaría disminuir un estándar de exigencia respecto de la extensión y profundidad de la fundamentación de la sentencia por medio del rechazo del recurso de casación, que es precisamente un elemento esencial de todo sistema de sana crítica.

La sentencia en este sentido no solo debe ser fundamentada, sino que dicha motivación debe ser a su vez suficiente y completa. Si dicha fundamentación no cumple con estas características se produce la vulneración de normas reguladoras de la prueba, lo cual solo podría ser reparado mediante la invalidación de la sentencia. Negar esta

${ }^{49}$ En el mismo sentido es posible encontrar pronunciamientos de la Corte Suprema Rol No $995-200$ de fecha 1 de octubre de 2002, en el Dictamen Contraloría General de la República No 6065 de 25 de enero de 2016 y en el Oficio No 1146 del Servicio de Impuestos Internos de fecha 27 de abril de 2015, entre otros.

${ }^{50}$ A partir de la autorización de la deducción como gasto del ejercicio de la pérdida de arrastre conforme dispone el artículo $31 N^{\circ} 3$ de la Ley de Impuesto a la Renta, el SII ha interpretado que una vez que esta sea fiscalizada, debe ser acreditada desde su origen incluso por sobre el plazo de prescripción extraordinaria de seis años contenido en el artículo 200 del Código Tributario. 
conclusión podría convertir el derecho a la prueba en una garantía ilusoria y ritualista, toda vez que no podría controlarse válidamente el razonamiento efectuado por el juez.

En el caso particular de la jurisprudencia emanada desde la Corte Suprema durante el 2016, si bien es posible compartir que gran parte del rechazo de los recursos de casación por denuncia de infracciones a las normas de la sana crítica se debe a la deficiente argumentación y desarrollo de los recursos por parte de los litigantes, no es menos cierto que la percepción de la Corte Suprema, respecto de la in/procedencia de la causal genera en ciertas ocasiones que, a efectos prácticos, no sea posible controlar la motivación de las sentencias por parte de los tribunales inferiores. Particularmente en aquellos casos donde no se advierte ausencia de motivación, sino más bien una motivación incompleta o insuficiente que deriva de fallos que contienen una mera enunciación de la prueba y no una valoración en los términos esperables o exigibles por la norma.

Como se ha insistido, este entendimiento se hace particularmente necesario al excluirse el recurso de casación en la forma por infracción al número $4^{\circ}$ del artículo 170 del Código de Procedimiento Civil, y concebirse el artículo 132 inciso $14^{\circ}$ del Código Tributario más bien como una norma ordenatoria litis y no decisoria litis, al indicar en reiterados fallos ya reseñados que en los procedimientos donde la prueba se valora conforme a las reglas de la sana crítica, la ponderación que con libertad pueden arribar los jueces de la instancia no es revisable por la vía de la nulidad sustantiva. Esta última percepción como norma ordenatoria litis, expuesta principalmente por el ministro Sr. Juica y la tesis desarrollada por la Corte Suprema para admitir la causal de casación por infracción a las reglas de la sana crítica, considerando como vicio solo la ausencia de motivos y no la motivación defectuosa o incompleta, es contraria a la doctrina ya revisada acerca de este punto, generando de paso un espacio de indefensión para los contribuyentes, toda vez que difícilmente se pueden advertir vicios de nulidad sustancial en los términos exigidos por la jurisprudencia del máximo Tribunal, si las sentencias defectuosas, con el fin de prevenir nulidad por falta de fundamentación, efectúan una relación de la prueba y reiteran frases de estilo para indicar que los medios de prueba han sido valorados racionalmente.

\section{UN DESARROLLO JURISPRUDENCIAL PENDIENTE: EL CONTROL DE LA MOTIVACIÓN INCOMPLETA, INSUFICIENTE O DEFECTUOSA COMO INFRACCIÓN A LAS NORMAS DE LA SANA CRÍTICA}

Según se señaló, la fundamentación de la sentencia es un elemento esencial de un sistema de valoración racional de la prueba. Esta fundamentación debe ser completa y clara respecto de los elementos probatorios aportados al juicio con el fin de que dicha sentencia pueda ser controlable principalmente respecto de tres aspectos: i) la existencia o ausencia de fundamentación; ii) la fundamentación in/completa; y iii) la motivación correcta/defectuosa ${ }^{51}$.

${ }^{51}$ El criterio de clasificación seguido ha sido el planteado por el profesor Javier Maturana (MATURANA, ob. cit., 2004, p. 273). 
Respecto de la ausencia de motivación es claro que ello constituye un vicio de nulidad, en algunos casos de forma más evidente, por ejemplo, si el sentenciador se remite solo a la descripción o enumeración de los elementos probatorios sin desarrollar ni justificar la decisión de la sentencia. La evolución jurisprudencial muestra que, si bien la ausencia de la motivación no ha sido erradicada totalmente, ella suele ser controlada de mejor forma por los tribunales de casación.

Por su parte, la motivación defectuosa dice relación con la existencia de sentencias cuya fundamentación es más bien incomprensible, incoherente o ilógica, ya sea porque el razonamiento efectuado por el juez resulta contradictorio o no es posible reproducirlo racionalmente porque presenta saltos argumentativos, razón por la que se asocia también a la infracción directa de los principios de la lógica.

Luego, en cuanto a la motivación incompleta, esta se presenta cuando no existe una motivación sobre los hechos, se omite la valoración de una prueba específica o no se expresan los criterios de inferencia realizados para la realización del razonamiento probatorio, impidiendo que dicho razonamiento pueda ser completamente reproducido. Una fundamentación completa exige que el juez se haga cargo de todas y cada una de las pruebas, exteriorizando en su sentencia las razones por las que las aprueba o las desestima. El vicio se produce principalmente por medio de: i) una valoración de prueba conjunta que no viene precedida de una valoración individual de la prueba y ii) la omisión en el criterio de inferencia lógica que permita el salto entre la existencia de una prueba y la determinación de un hecho probado. El otro caso de motivación incompleta dice relación con la falta de expresión de la máxima de la experiencia o el conocimiento científicamente afianzado en el que el juez basa su decisión, lo que al igual que los otros vicios de la fundamentación, impide la reconstrucción del razonamiento llevado a cabo por el juez.

El problema del uso de un criterio restrictivo para la admisión de la causal, podría derivar en la inexistencia de un control real sobre la fundamentación del razonamiento, lo que en ciertas ocasiones ha dado lugar o permitido que se generen sentencias en las que los jueces se limitan a señalar escuetamente que la prueba ha sido apreciada en conciencia $^{52}$, cuestión que deviene no solo en una errada idea de la discrecionalidad y de la obligación argumentativa que pesa sobre el adjudicador de refinar el canon de valoración, sino que por el contrario lo alienta a repetir cláusulas de estilo ${ }^{53}$, cuestión que deriva en la omisión real de las razones de justificación de la sentencia, es decir: Se trata, de un modelo que elude explicitar las razones justificativas del valor atribuido a cada medio de prueba así como de su suficiencia (o insuficiencia) para dar (o no dar) por acreditados

52 GonZÁlez, Joel. "La fundamentación de las sentencias y la sana crítica". En Revista Chilena de Derecho. Volumen $33 \mathrm{~N}^{\circ} 1,2006$, p. 94.

${ }^{53}$ Larroucau, Jorge. La Prueba en el Proceso Civil. Tesis para optar al grado de Doctor en Derecho, Facultad de Derecho, Universidad de Chile, 2010, p. 202. 
los hechos constitutivos del caso y que omite, por regla general, cualquier referencia a la prueba desestimada 5455 .

En este sentido, una cuestión relevante dice relación con definir cuál ha de ser la función de un tribunal de casación respecto de la correcta aplicación del derecho. Este control solo podría efectuarse válidamente si el razonamiento efectuado por el juez es reproducible lógicamente. Luego, para que un razonamiento cumpla con dicha característica es necesario, desde luego, que al menos sea efectuado.

Un problema común de algunos fallos de las Cortes de Apelaciones en materia tributaria, controlados por la vía del recurso de casación en el fondo por la Corte Suprema, se refiere a la efectiva revisión de los antecedentes aportados por las partes. Al respecto, la Corte de Apelaciones de Santiago ha señalado en ocasiones que la documentación contable es materia de análisis de una fiscalización administrativa y de un tribunal de primera instancia y no de una Corte ${ }^{56}$, expresando que no puede pretender el contribuyente que se efectúe una especie de peritaje sobre la prueba aportada ${ }^{57}$.

Este problema puede derivar en que la negativa de la revisión de la prueba genere un sistema que carezca de control de fundamentación real, permitiendo la emisión de sentencias que se limiten únicamente a la enunciación de la prueba y a la utilización de expresiones genéricas como valorada la prueba en conciencia o de acuerdo a las normas de la sana crítica que no permiten reproducir el razonamiento utilizado por el juez para la fundamentación del fallo. En estos casos, si bien no resulta denunciable la omisión de la fundamentación, sí existen problemas de defectos y falta de fundamentación,

${ }^{54}$ Accatino, Daniela. "La fundamentación de la declaración de hechos probados en el nuevo proceso penal. Un diagnóstico”, en Revista de Derecho Vol. XIX, No 2, diciembre 2006, p. 11.

55 En este sentido, si bien la profesora Accatino plantea la crítica para a sentencias en materia penal para la plantear el desafió de delimitar el alcance de fundamentación de las sentencias para el Nuevo Proceso Penal, la estructura actual de las sentencias de los Tribunales Tributarios y Aduaneros es más o menos similar a la señalada por la autora, quien, citando a Hanisch, H., indica que un modelo típico de sentencia que no explicite correctamente su razonamiento, en cualquier área del derecho, habitualmente se compone de los siguientes elementos: a) la inclusión de abultadas partes expositivas en las que se consignaban detalladamente cada una de las actuaciones procesales tendientes al esclarecimiento de los hechos; b) la enumeración de los medios de prueba estimados por el tribunal; c) la declaración de los hechos que se tienen por probados (o, en su caso, por no probados), unida a la afirmación de que el conjunto de medios probatorios que antes se ha enumerado, apreciados conforme a las reglas legales, es suficiente (o, en su caso, insuficiente) para tenerlos por acreditados." Al respecto ver: HanisCH, H., "Contribución al estudio del principio y de la práctica de fundamentación de las sentencias en Chile durante el siglo XIX”, en Revista de Estudios histórico-jurídicos, VII, 1982, pp. 131-173.

${ }^{56}$ No obstante existe mandato expreso del legislador no solo para revisar la prueba, sino también para la revisión exclusiva de causas en materia tributaria por salas especializadas.

57 Por ejemplo, Corte de Apelaciones de Santiago, Rol N ${ }^{\circ} 175-2015$ de 16 de marzo de 2016. El caso resulta bastante especial, por cuanto la mención a la norma de la sana crítica se enfoca en señalar que conforme a dichas reglas de valoración no es posible arribar a una conclusión distinta a la del sentenciador de primera instancia. Sin embargo, de forma previa la sentencia explica que la mayor parte de los antecedentes han sido aportados en segunda instancia antes de la vista de la causa, cuestión que permitiría bajo su visión rechazar el recurso. 
los que, de acuerdo con la posición de la doctrina, pueden ser objeto de nulidad sustancial $^{58}$. Así: Sin una fundamentación que sea clara y completa, es imposible determinar si los hechos se ban establecido sin infringir los principios de la lógica, las máximas de la experiencia y los conocimientos científicamente afianzados, por el simple motivo de que sin las razones que llevaron a tal establecimiento se desconoce cómo se llevó a cabo el mismo (...) Por esta razón, la fundamentación no sólo constituye un presupuesto para controlar que se cumplan las exigencias legales en la valoración, sino que la motivación misma pasa a constituir una exigencia legal cuya infracción hace que la sentencia sea anulable y controlable mediante los recursos de casación y/o nulidad 59 .

Finalmente, en el mismo sentido: La doctrina ha precisado que no basta con cualquier motivación para satisfacer las exigencias constitucionales; es indispensable que sea completa, esto es, abarcar todos los aspectos fácticos y jurídicos de la decisión. En concreto, se trata que el razonamiento para determinar la verdad de un enunciado fáctico pueda encontrarse suficiente y adecuadamente justificado con las pruebas producidas en el proceso. El razonamiento justificativo tiene que ser apto para demostrar que los enunciados declarados verdaderos tienen un sustento en el material probatorio. De abi que el juez deba analizar, valorar y ponderar todos los medios de prueba generados en el proceso (... ${ }^{60}$.

\section{CONCLUSIONES}

Es posible que una correcta aplicación por parte de la jurisdicción tributaria del sistema de valoración racional de la prueba requiera de algunos años más de práctica y estudio, siendo muy temprano para evaluar su éxito o fracaso. .Sin embargo, ya se observan problemas asociados a la valoración y revisión racional de la prueba, derivados del carácter eminentemente técnico y el volumen de la misma sobre todo en aquellos juicios que buscan la acreditación de un resultado tributario en un extenso período, lo que incide directamente en la extensión y profundidad de la motivación de la sentencia. En estos casos, usualmente las referencias a la sana crítica no constituyen una real manifestación de un razonamiento racional reproducible por terceros como un control de valoración de la prueba.

Frente a esta constatación, la jurisprudencia de nuestra Corte Suprema ha evidenciado uncriterio restrictivo, tanto para la admisibilidad como acoger por razones de fondo los recursos de casación sustantivos en materia tributaria cuando lo que se denuncia como infringido es la norma reguladora de la prueba contenida en el artículo 132 inciso $14^{\circ}$ del Código Tributario, lo que se explica no solo por el carácter excepcional de la revisión de los hechos en un recurso de derecho estricto como el recurso de casación, sino también por la incorrecta utilización de esta causal y el recurso por parte de los litigantes que, buscando con este una revisión de los hechos en una especie de tercera instancia,

${ }^{58}$ Ferrer, Jordi. Prueba y Verdad en el Derecho. Editorial Marcial Pons, 2002, p. 28.

${ }^{59}$ Maturana, Javier. ob. cit., p. 376.

${ }^{60}$ Hunter, Iván. "Control Judicial de Las Reglas de la Sana Crítica (Corte Suprema)”. Revista de Derecho de Valdivia, Volumen 25 N $^{\circ} 1,2012$, p. 251. 
han generado una multiplicidad de recursos de casación que a ratos desvirtúan el sentido de su existencia como forma de uniformar y controlar la correcta aplicación del derecho. Ello ha tenido como consecuencia que del total de las sentencias revisadas en el presente trabajo, la totalidad de los recursos interpuestos por infracción al artículo 132 inciso 14 del Código Tributario hayan sido rechazadas.

No obstante lo anterior, se debe considerar como contrapunto la imposibilidad por parte de los litigantes tributarios de denunciar la omisión de fundamentación de la sentencia, de conformidad a lo establecido en el número 4 del artículo 170 del Código de Procedimiento Civil, como causal para interponer un recurso de casación en la forma por la causal del número 5 del artículo 768 del mismo Código, cuestión que deriva en que la única forma de impugnar y controlar la motivación de la sentencia sea precisamente el recurso de casación en el fondo por infracción al inciso 14 del artículo 132 del Código Tributario.

Como hemos indicado, el deber de fundamentación de las sentencias es un principio fundamental en un sistema de valoración racional de la prueba. Este deber, que permite controlar por la vía de los recursos procesales el razonamiento llevado a cabo por el juzgador, no solo debe cumplir con la motivación en tanto enunciación de los medios de prueba, sino que esta fundamentación debe contenerse en el fallo de forma completa y suficiente valorando todos los medios de prueba aportados por las partes al proceso. Es decir, una infracción al deber de fundamentación no solo se produce cuando se ha omitido totalmente la motivación en la sentencia o una parte de ella, sino cuando esta ha sido defectuosa, incompleta o insuficiente al impedir la reproducción del razonamiento utilizado por el juez.

En este sentido, un aspecto no desarrollado por la jurisprudencia revisada lo constituye el control de la casación respecto de la motivación defectuosa o insuficiente y no solo la completa omisión de la fundamentación. Ello, por cuanto si el estándar de exigencia para la aceptación del recurso es tal que requiere encontrar de forma explícita la regla de la sana crítica infringida, ello solo será posible en la medida en que la sentencia sea precisamente fundamentada, cuestión que no ocurrirá si el tribunal inferior se limita únicamente a la enunciación de la prueba aportada y concluye su justificación con la utilización de frases de estilo.

\section{BIBLIOGRAFÍA}

Accatino, Daniela. "La fundamentación de la declaración de hechos probados en el nuevo proceso penal. Un diagnóstico”. En Revista de Derecho Vol. XIX, No 2, diciembre 2006, pp. 9-26.

Ascencio, Félix. Revisión de los hechos y recursos de nulidad. Memoria para optar al grado de Licenciado en Ciencias Jurídicas y Sociales, Universidad de Chile. Santiago, 2005.

Benavides, Álvaro. Procedencia de una nueva auditoría en el procedimiento general de reclamaciones. Tesis de grado para optar al grado de Magíster en Tributación, Facultad de Economía y Negocios, Universidad de Chile, 2014.

Coloma, Rodrigo. "Panorama general de la Prueba en el Juicio Oral Chileno". En Coloma, Rodrigo, La Prueba en el Nuevo Proceso Penal, Editorial Lexis Nexis, Santiago, Chile, 2003. 
Coloma, Rodrigo. “¿Realmente importa la sana crítica?”. En Revista Chilena de Derecho. Vol. 39 $\mathrm{N}^{\circ} 3,2012$.

Couture, Eduardo. Fundamentos de Derecho Procesal Civil. Ediciones de Palma, Buenos Aires, Argentina. 1985.

Ferrer, Jordi. "Derecho a la prueba y racionalidad de las decisiones judiciales". En Jueces para la democracia, ISSN 1133-0627, No 47, 2003, pp. 27-34.

Ferrer, Jordi. Prueba y Verdad en el Derecho. Editorial Marcial Pons, 2002.

Ferrer, Jordi. La valoración racional de la prueba. Editorial Marcial Pons, Madrid, España, 2007.

Gascón, Marina. Los hechos en el derecho: Bases argumentales de la prueba. Segunda edición, editorial Marcial Pons, Madrid, España, 2004.

Greiber, Pablo, Ocampo, Luis Felipe y Seguel, Luis. "Justicia Tributaria y Delegación de Facultades Jurisdiccionales: Análisis de la Jurisprudencia reciente del Tribunal Constitucional”. En Anuario de Doctrina y Jurisprudencia, Sentencias Destacadas, año 2006, Instituto Libertad y Desarrollo. Santiago, abril de 2007.

GonZÁlez, Joel. "La fundamentación de las sentencias y la sana crítica". En Revista Chilena de Derecho. Volumen $33 \mathrm{~N}^{\circ} 1,2006$.

Horvitz, María Inés y López, Julián. Derecho Procesal Penal. Editorial Jurídica de Chile. Santiago, 2004. Tomo II.

Hunter, Iván. "Control Judicial de Las Reglas de la Sana Crítica (Corte Suprema)". Revista de Derecho de Valdivia, Volumen 25 No 1, 2012, pp. 243-251.

Larroucau, Jorge. La Prueba en el Proceso Civil. Tesis para optar al grado de Doctor en Derecho, Facultad de Derecho, Universidad de Chile, 2010.

Maturana, Javier. Sana Crítica, un sistema de valoración racional de la prueba. Editorial Thomson Reuters. 2014.

Mosquera, Mario y Maturana, Cristián. Los Recursos Procesales. Editorial Jurídica de Chile. Segunda edición, Santiago, 2013.

Navarro, René. Bases para una sana crítica. Lógica, interpretación, argumentación, máximas de la experiencia, conocimiento científico (un ensayo). RIL Editores, abril de 2014.

Stein Friedrich. El Conocimiento Privado del Juez. Traducción por Andrés de la Oliva. Editorial Temis, Bogotá, Colombia. 1988.

Taruffo, Michele. La prueba de los hechos. Editorial Trotta. Traducción de Jordi Ferrer Beltrán, Madrid, España, 2002.

Taruffo, Michele. La Prueba. Marcial Pons, 2008.

Taruffo, Michele. “Ciencia y Proceso”. En Páginas Sobre Justicia Civil, Marcial Pons, 2009.

TARuffo, Michele. Verdad, prueba y motivación en la decisión sobre los hechos. Serie de cuadernos de divulgación de la justicia electoral. México, 2013.

Vergara, Gonzalo. "El reclamo tributario: Características esenciales de un recurso contenciosoadministrativo de plena jurisdicción”. En Revista No 10 del Centro de Estudios Tributarios de la Universidad de Chile, 2014, pp. 178-208.

\section{Sentencias citadas de la Corte Suprema de Chile}

Rol $N^{\circ}$ 13.693-15 de 23 de diciembre de 2015, "Servicio de Impuestos Internos VIII DR Concepción con Constructora Krohnnilsen Limitada".

Rol N $N^{\circ} 24.611-14$ de 7 de enero de 2016, "Pirotecnia Igual Chile S.A. con S.I.I.".

Rol No 4.879-15 de 21 de enero de 2016, "Altamirano Zárate Mario Eduardo con S.I.I. Valparaíso". Rol $\mathrm{N}^{\circ} 30.320-14$ de 25 de enero de 2016, "Ñuble Ingeniería S.A. con S.I.I.”. 
Rol N ${ }^{\circ} 1732-15$ de 25 de enero de 2016, "Sociedad Constructora Proessa Ltda. con S.I.I. VII Dirección Regional Talca".

Rol $\mathrm{N}^{\circ} 1522-15$ de 28 de enero de 2016, "Inversiones Tiempos Nuevos Ltda. con S.I.I.".

Rol No 31.299-15 de 28 de enero de 2016, "Centro Veterinario y Agrícola Limitada con Servicio de Aduanas Dirección Regional de Valparaíso".

Rol No 3606-15 de 17 de marzo de 2016, "GTD Chile Ingeniería de Sistemas S.A. con Servicio Nacional de Aduanas".

Rol No 3364-15 de 22 de marzo de 2016, "Ibacache Espinoza Secundino del Tránsito con S.I.I. La Serena".

Rol N N $^{\circ}$ 1961-15 de 23 de marzo de 2016, "EFCO Servicios Generales S.A. con S.I.I.".

Rol N ${ }^{\circ} 2996-15$ de 23 de marzo de 2016, "Guido del Tránsito Ibacache con S.I.I. La Serena".

Rol N ${ }^{\circ}$ 5379-16 de 28 de marzo de 2016, "Elgueta y Elgueta Limitada con Tesorería General de la República".

Rol N N $^{\text {3266-15 de }} 18$ de abril de 2016, "Sotraker Molina con S.I.I. Dirección Regional Punta Arenas".

Rol N N $^{\circ}$ 17.075-16 de 20 de abril de 2016, "Servicio de Impuestos Internos Regional Norte / Varela Barrientos Marcelo Alexis”.

Rol N N $^{\circ}$ 7507-16 de 20 de abril de 2016, "Granotade S.A. con Servicios de Impuestos Internos IX Dirección Regional".

Rol N $N^{\circ} 2866-2015$ de 21 de abril de 2016, “Asesorías e Inversiones Ritoque Ltda. con S.I.I.”.

Rol No 7092-2015 de 25 de abril de 2016, “Agrícola y Comercial GM Limitada con S.I.I.”.

Rol N $\mathrm{N}^{\circ}$ 24309-16 de 4 de mayo de 2016, "Reclamante: Artel S.A.I.C. con Servicio de Aduanas Dirección Regional de Valparaíso”.

Rol No 8318-15 de 16 de mayo de 2016, “Ávila y Salazar Compañía Ltda.con S.I.I.”.

Rol No 8004-15 de 24 de mayo de 2016, "Ingeniería y Construcción Valmar Ltda. con S.I.I., Direcc. Regional Concepción".

Rol No 8214-15 de 24 de mayo de 2016, "Carrizo Carrizo Alejandro con S.I.I.".

Rol $N^{\circ} 10.241-15$ de 1 de junio de 2016, "Wilson Ramos Santa María con S.I.I. La Serena".

Rol N ${ }^{\circ} 10.174-15$ de 2 de junio de 2016, "Constructora V.YA. Limitada con S.I.I. VIII DR Concepción".

Rol No 31.161-16 de 13 de junio de 2016, "Pamela Albornoz Badilla con Servicio de Impuestos Internos".

Rol N N $^{\circ}$ 14.912-15 de 1 de agosto de 2016, "Empresa Constructora Precon S.A. con S.I.I.".

Rol No 8314-2015 de 2 de agosto de 2016, "Sociedad Constructora El Arrayán Ltda. con S.I.I. IX Dirección Regional”.

Rol N $N^{\circ} 28.384-15$ de 5 de septiembre de 2016, " S.I.I. con Proelec S.P.A.”.

Rol N $\mathrm{N}^{\circ}$ 52947-16 de 6 de septiembre de 2016, "Corporación ZTE de Chile S.A. / Servicio de Impuestos Internos Santiago Sur".

Rol N ${ }^{\circ}$ 55155-16 de 6 de septiembre de 2016, "Eyzaguirre Aravena / Servicio de Impuestos Internos Santiago Oriente".

Rol N ${ }^{\circ}$ 26854-14 de 15 de septiembre de 2016, "Plásticos Técnicos S.A con S.I.I. XVI DR Santiago Sur".

Rol N ${ }^{\circ}$ 1474-15 de 4 de abril de 2016, "Soc. Agrícola y Ganadera Lácteos Tronador Ltda. con Servicio de Impuestos Internos".

Rol N N $^{\circ}$ 17727-16 de 20 de abril de 2016, "Forestal Santa Laura Limitada / Servicio de Impuestos Internos".

Rol No 23719-16 de 4 de mayo de 2016, "Caimi Corp S.A. con Servicio de Impuesto Internos V DR. Valparaíso". 
Rol N 27.707-16 de 13 de junio de 2016, "Rolando Iturra Fernández contra Servicio de Impuestos Internos IX Dirección Regional".

Rol N² 28.570-16 de 13 de junio de 2016, "Cultivos Acuáticos Manantiales S.A. / Servicio de Impuestos Internos Santiago Oriente".

Rol No 34828-16 de 22 de junio de 2016, "Pablo Larraín y Compañía / Servicio de Impuestos Internos Dirección Regional Santiago Poniente".

Rol N 6327-15 de 28 de junio de 2016, "Pérez Nagel y Otro con Servicio Aduana Dirección Regional Iquique".

Rol No 8.109-15 de 30 de junio de 2016, "Servicio de Elevación y Transporte Mammoet Chile y Compañía Limitada con Dirección Regional de Aduanas de Arica y Parinacota".

Rol No 11.183-15 de 30 de junio de 2016, "Guzmán Ricardi Sylvia con S.I.I.".

Rol $N^{\circ} 7.852-15$ de 6 de julio de 2016, "Diócesis de Villarrica de la Iglesia Católica con S.I.I.". Rol N $\mathrm{N}^{\mathrm{7}}$ 7424-16 de 11 de julio de 2016, "Sociedad Agrícola Las Mercedes Ltda. con S.I.I.".

Rol N ${ }^{\circ}$ 10.048-15 de 11 de julio de 2016, "Inmobiliaria Peñablanca S.A. con S.I.I.".

Rol No 8.815-15 de 12 de julio de 2016, "Agrícola Paumac Limitada con S.I.I.".

Rol N $N^{\circ}$ 9.113-15 de 13 de julio de 2016, "Martínez Acuña Luis Alberto con S.I.I. V DR. Valparaíso".

Rol N ${ }^{\circ}$ 6.184-15 de 19 de julio de 2016, "Técnicas Modulares e Industrias Chile Limitada con S.I.I. XIV Santiago Poniente".

Rol No 7257-2015 de 19 de julio de 2016, "Humberto Ignacio Miguel Cerda con S.I.I., Direcc. Regional Concepción".

Rol N $N^{\circ} 991-15$ de 2 de agosto de 2016, "Fundación Solidaridad con S.I.I.”.

Rol No 14.615-15 de 8 de agosto de 2016, "Cooperativa Agrícola Profesor Juan Noé Crevani Limitada con S.I.I., Dirección Regional de Arica y Parinacota”.

Rol No 20.174-15 de 8 de agosto de 2016, “Biotex SA con S.I.I. Dirección Regional Punta Arenas”.

Rol N $\mathrm{N}^{\circ}$ 10.091-15 de 23 de agosto de 2016, "Serviclínica Iquique S.A. con S.I.I. Dirección Regional Iquique y Otro".

Rol N N $^{\circ} 2879-16$ de 25 de agosto de 2016, "Reclamante Sociedad Agrícola Forestal Temos Limitada con Servicio de Impuestos Internos IX Dirección Regional”.

Rol N N $^{\circ} 6252-15$ de 5 de septiembre de 2016, "Ahumada Ramos José con S.I.I. Valparaíso".

Rol N ${ }^{\circ}$ 58868-16 de 6 de septiembre de 2016, "Reclamante Servicios Enter Staff Limitada con Servicio de Impuestos Internos IX Dirección Regional".

Rol N $\mathrm{N}^{\circ}$ 10.361-15 de 12 septiembre de 2016, "Inversiones Cemento Bío Bío S.A. con S.I.I. Direc. Regional Concepción".

Rol N ${ }^{\circ}$ 13160-15 de 12 de septiembre de 2016, "Inversiones Nueva Llanten Ltda. con S.I.I.".

Rol No 65263-16 de 21 de septiembre de 2016, "Noemi Callejas Paulino / Servicio de Impuestos Internos".

Rol N $\mathrm{N}^{\circ}$ 65.271-16 de 21 de septiembre de 2016, "Callejas Miranda Norma / Servicio de Impuestos Internos DR. Stgo. Poniente".

Rol No 26.914-15 de 22 de septiembre de 2016, "Comercializadora Andina S.A. con S.I.I.".

Rol N ${ }^{\circ}$ 26.652-2015 de 6 de octubre de 2016, "María Angélica Vidal Toledo contra S.I.I. Dirección Regional Punta Arenas".

Rol No 24.750-2015 de 11 de octubre de 2016, "Sociedad Comercial y de Servicios de Entretenimiento Progame Ltda. con S.I.I. IX Dirección Regional”.

Rol N $\mathrm{N}^{\circ}$ 26.911-15 de 11 octubre de 2016, "Transportes y Servicios Cordaro Ltda. con S.I.I.".

Rol No 18.136-2015 de 12 de octubre de 2016, "Feria Ganaderos Osorno S.A. con S.I.I.".

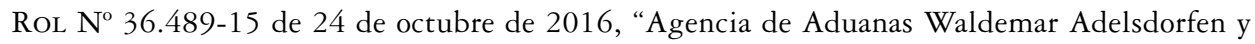
Cía. Ltda. con S.I.I. V DR. Valparaíso”. 
Rol N N $^{\text {76347-16 de }} 26$ de octubre de 2016, "Sociedad Educacional Innovación Ltda. con Servicio de Impuestos Internos".

Rol No 84782-16 de 17 de noviembre de 2016, "Servicio de Impuestos Internos / Servicios Facility Chile S.A.".

Rol No 42-16 de 29 de noviembre de 2016, "Nicasio Eduardo Martínez Oggero con S.I.I. VIII DR Concepción".

RoL No 37.181-15 de 29 noviembre 2016, "Alid Aleuy Ricardo con S.I.I.".

Rol $N^{\circ} 12.874-15$ de 7 de diciembre de 2016, "Feria Ganaderos Osorno S.A.con S.I.I.".

Rol $\mathrm{N}^{\circ}$ 34.171-2015 de 22 de diciembre de 2016, "Clara de las Mercedes Bensan Jofré con S.I.I.". Rol $\mathrm{N}^{\circ}$ 16.597-16 de 29 de diciembre de 2016, "Inversiones Nueva Llanten Ltda. con S.I.I.".

\section{Sentencias citadas del Tribunal Constitucional de Chile}

Rol N ${ }^{\circ} 1873-10$ de 25 de agosto de 2011, "Requerimiento de inaplicabilidad por inconstitucionalidad presentado por Inversiones Rotondo Limitada respecto del inciso segundo del artículo 768 del Código de Procedimiento Civil, en los autos Rol No 8583-2009 sobre reclamo de ilegalidad interpuesto ante la Corte de Apelaciones de Santiago en contra de Municipalidad de Las Condes".

Rol No 2529-13 de 2 de enero de 2015, "Requerimiento de inaplicabilidad por inconstitucionalidad presentado por Hoteles de Chile S.A. respecto del inciso segundo del artículo 768 del Código de Procedimiento Civil, en los autos caratulados 'Hoteles de Chile S.A. con Servicio de Impuestos Internos', de que conoce la Corte Suprema por recursos de casación en la forma y en el fondo, bajo el Rol No 7109-2013".

Rol N N $^{\circ}$ 2677-14 de 4 de junio de 2015, "Requerimiento de inaplicabilidad por inconstitucionalidad presentado por Sociedad Plasma Limitada y otro respecto del inciso segundo del artículo 768 del Código de Procedimiento Civil, en los autos caratulados 'Comunidad Edificio Baquedano con Plasma Ltda. y otro', de que conoce la Corte Suprema por recursos de casación en la forma y en el fondo, bajo el Rol No 11.319-2014".

Rol $\mathrm{N}^{\circ}$ 2873-15 de 21 de julio de 2016, "Requerimiento de inaplicabilidad por inconstitucionalidad presentado por Plásticos Técnicos S.A. respecto del inciso antepenúltimo del artículo 768 del Código de Procedimiento Civil, en los autos sobre recursos de casación en la forma y en el fondo, caratulados 'Plásticos Técnicos S.A. con Servicio de Impuestos Internos', de que conoce la Corte Suprema, bajo el Rol No 26.854-2014".

Rol N N $^{\circ} 2898-15$ de 21 de julio de 2016, "Requerimiento de inaplicabilidad por inconstitucionalidad respecto de la parte que indica del artículo 768, inciso segundo, del Código de Procedimiento Civil, en el marco de los recursos de casación en la forma y en el fondo Rol $\mathrm{N}^{\circ} 12874-2015$ de la Corte Suprema". 